(c) 2003 American Chemical Society, Org. Lett., Werner ol035214a Supporting Info Page 1

\title{
Appendix
}

\section{A) SYNTHESIS}
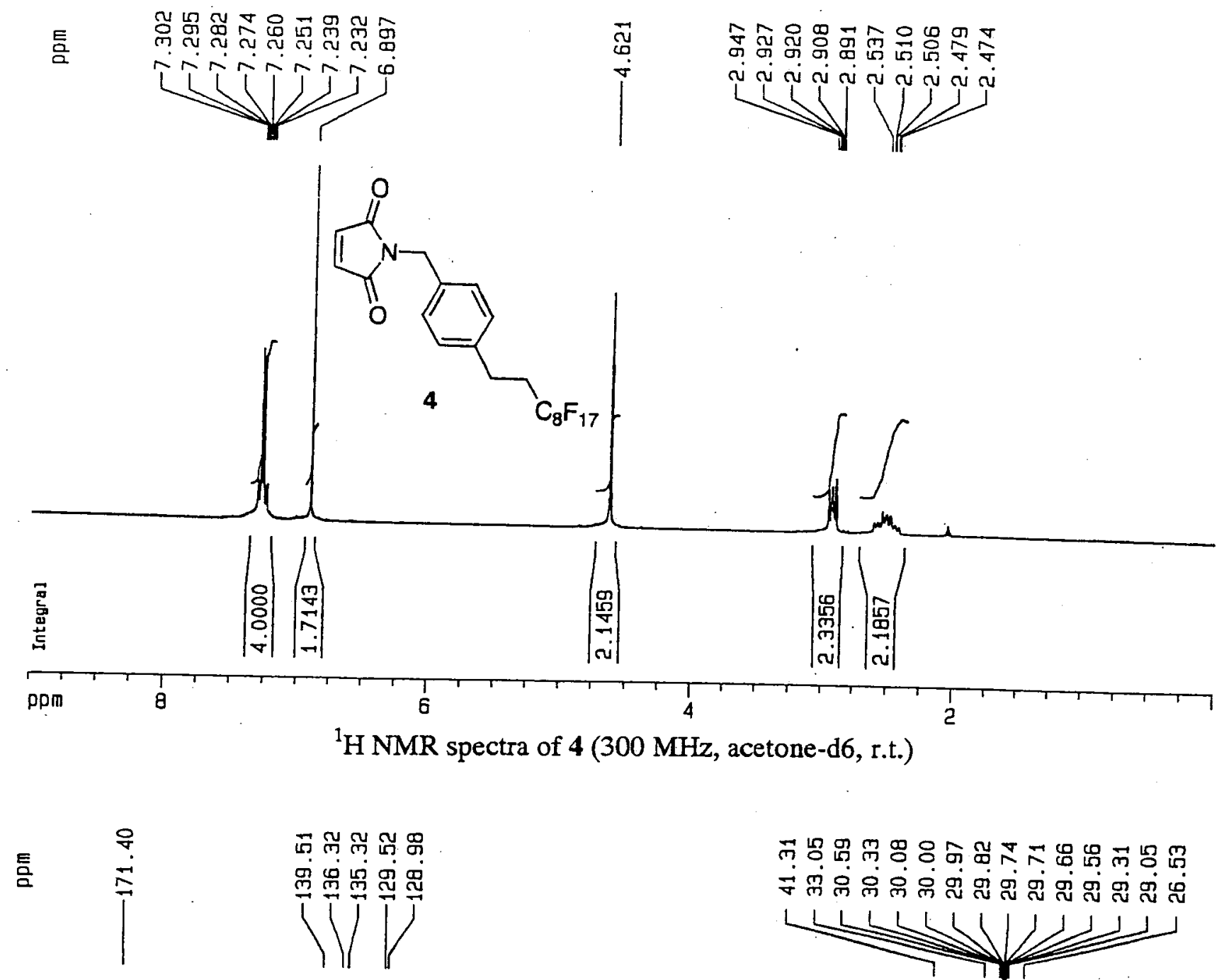

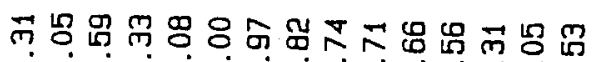

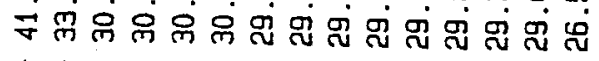
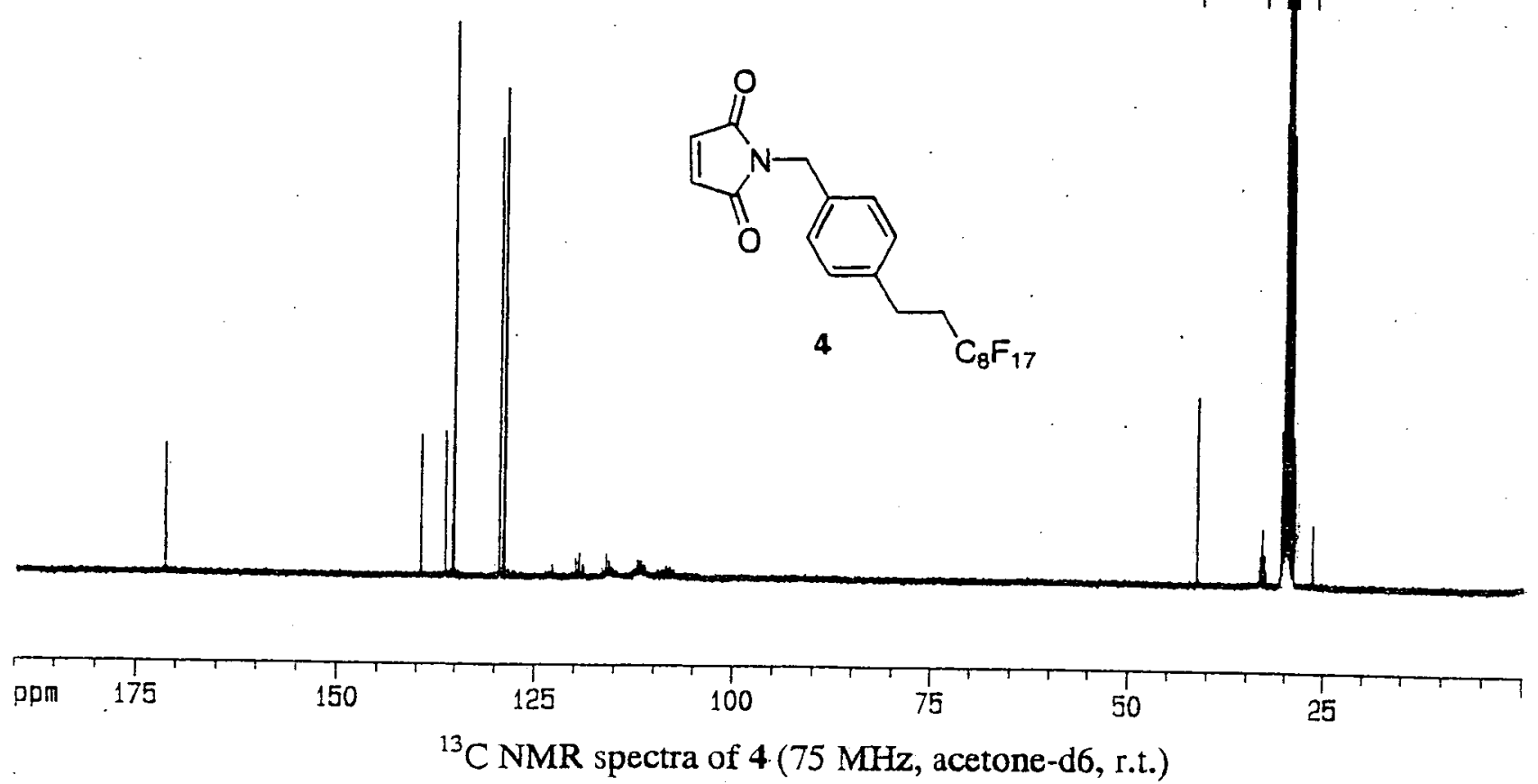
(C) 2003 American Chemical Society, Org. Lett., Werner ol035214a Supporting Info Page 2

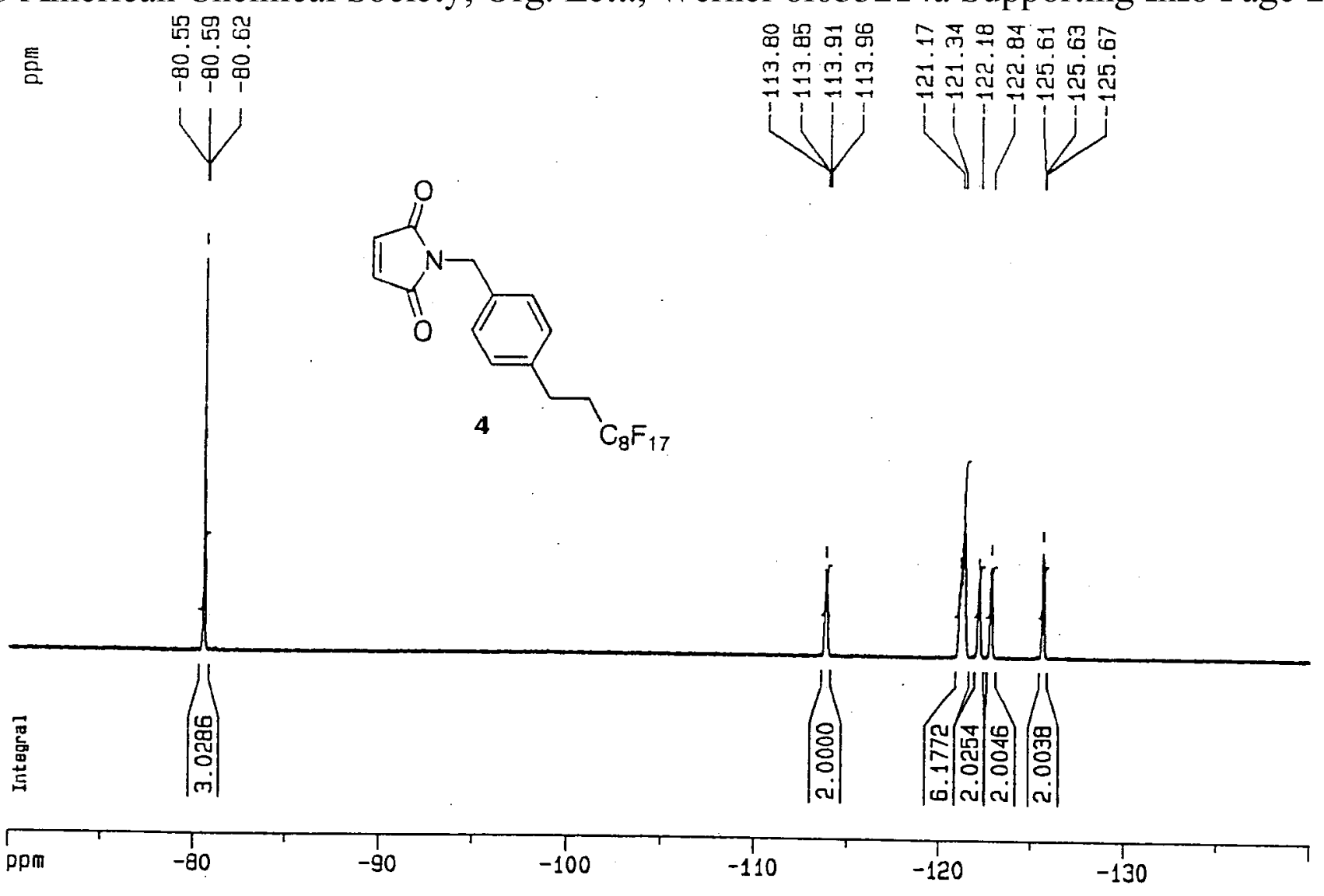

${ }^{19} \mathrm{~F}$ NMR spectra of 4 (282 MHz, acetone-d6, r.t.)

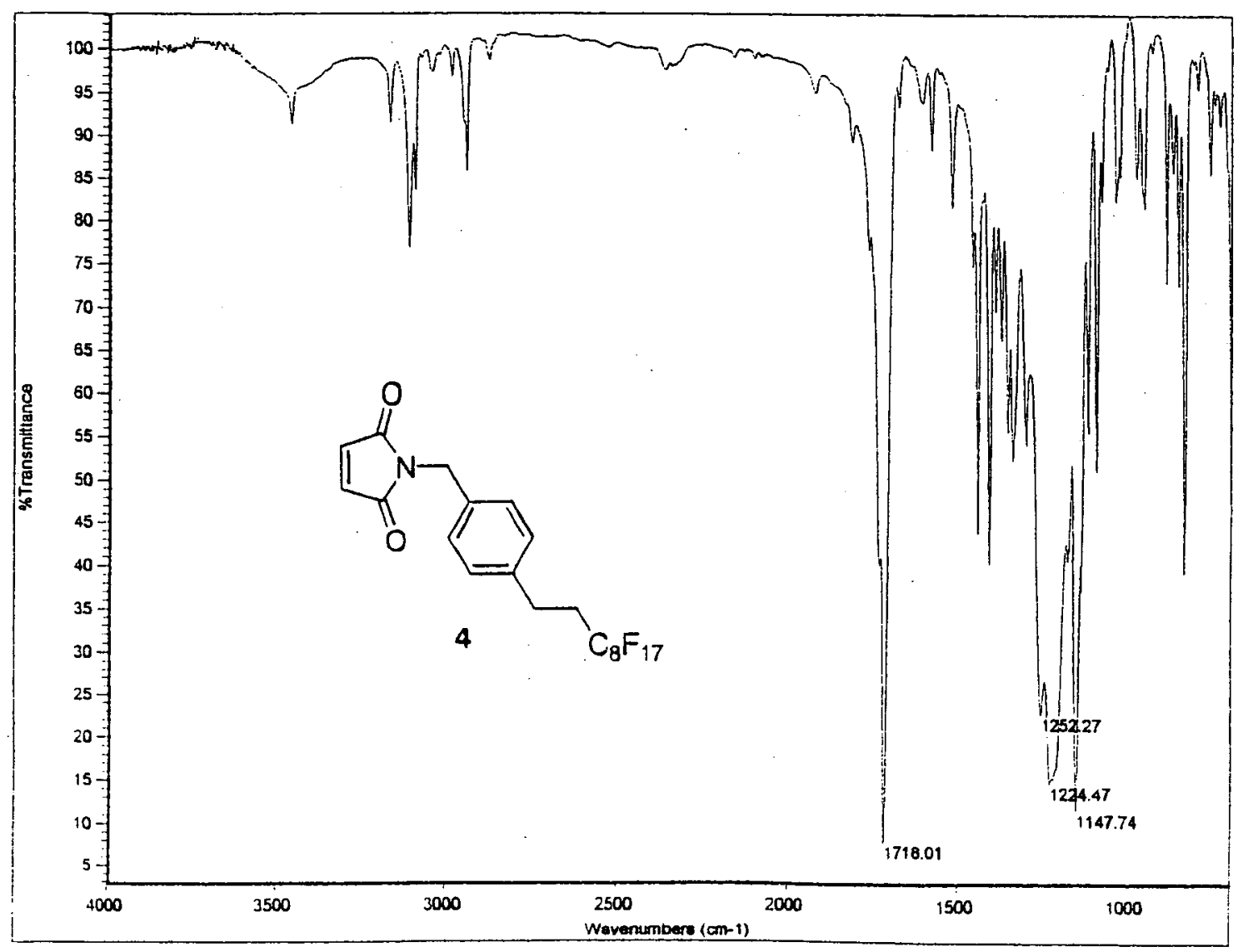

IR spectra of $4(\mathrm{KBr})$

S-15 
(C) 2003 American Chemical Society, Org. Lett., Werner ol035214a Supporting Info Page 3
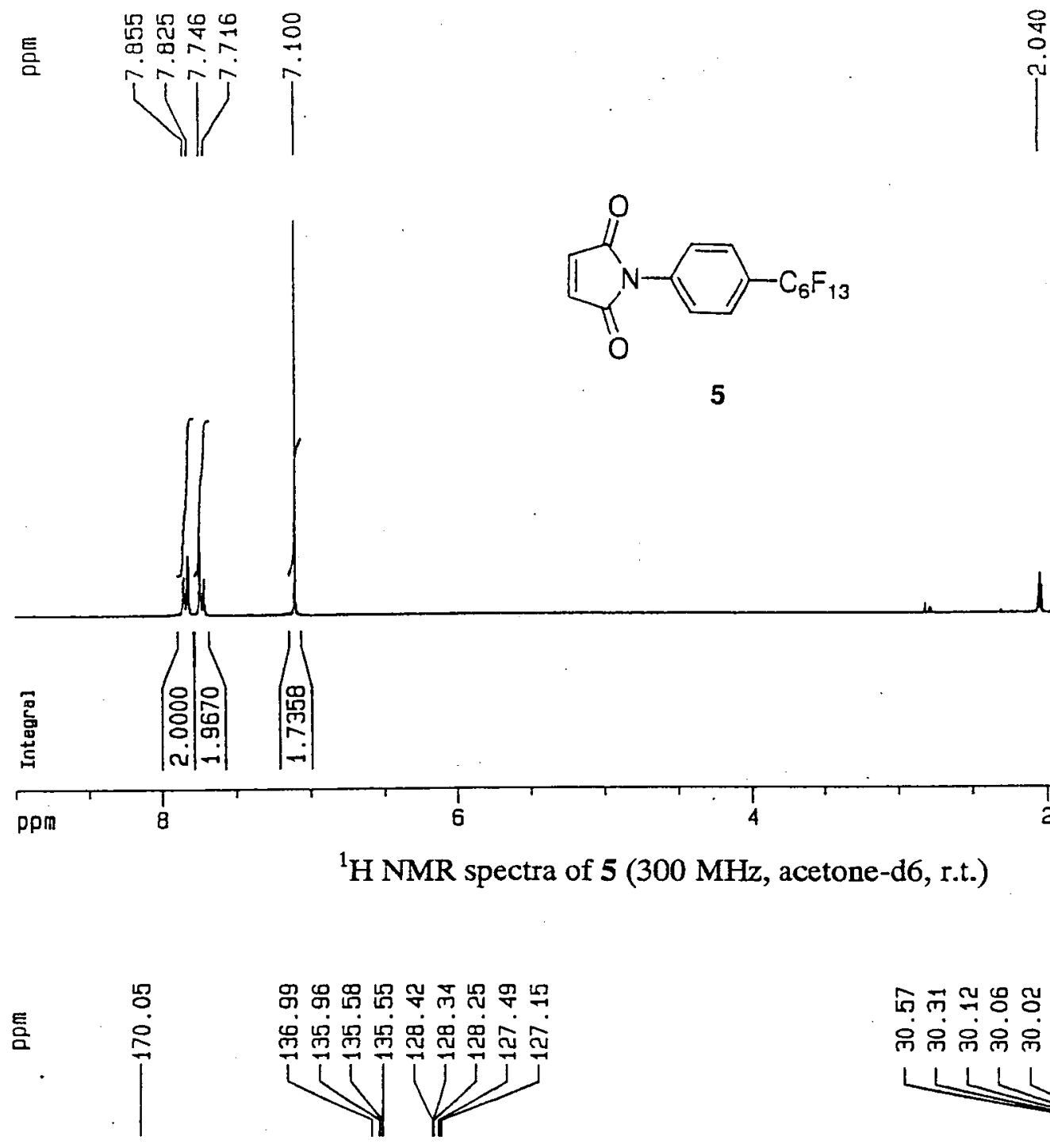

5
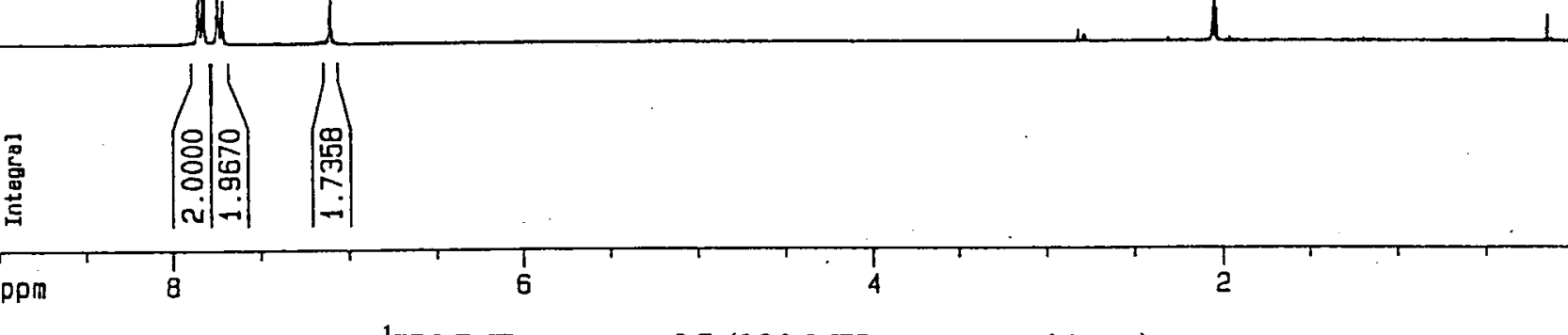

2
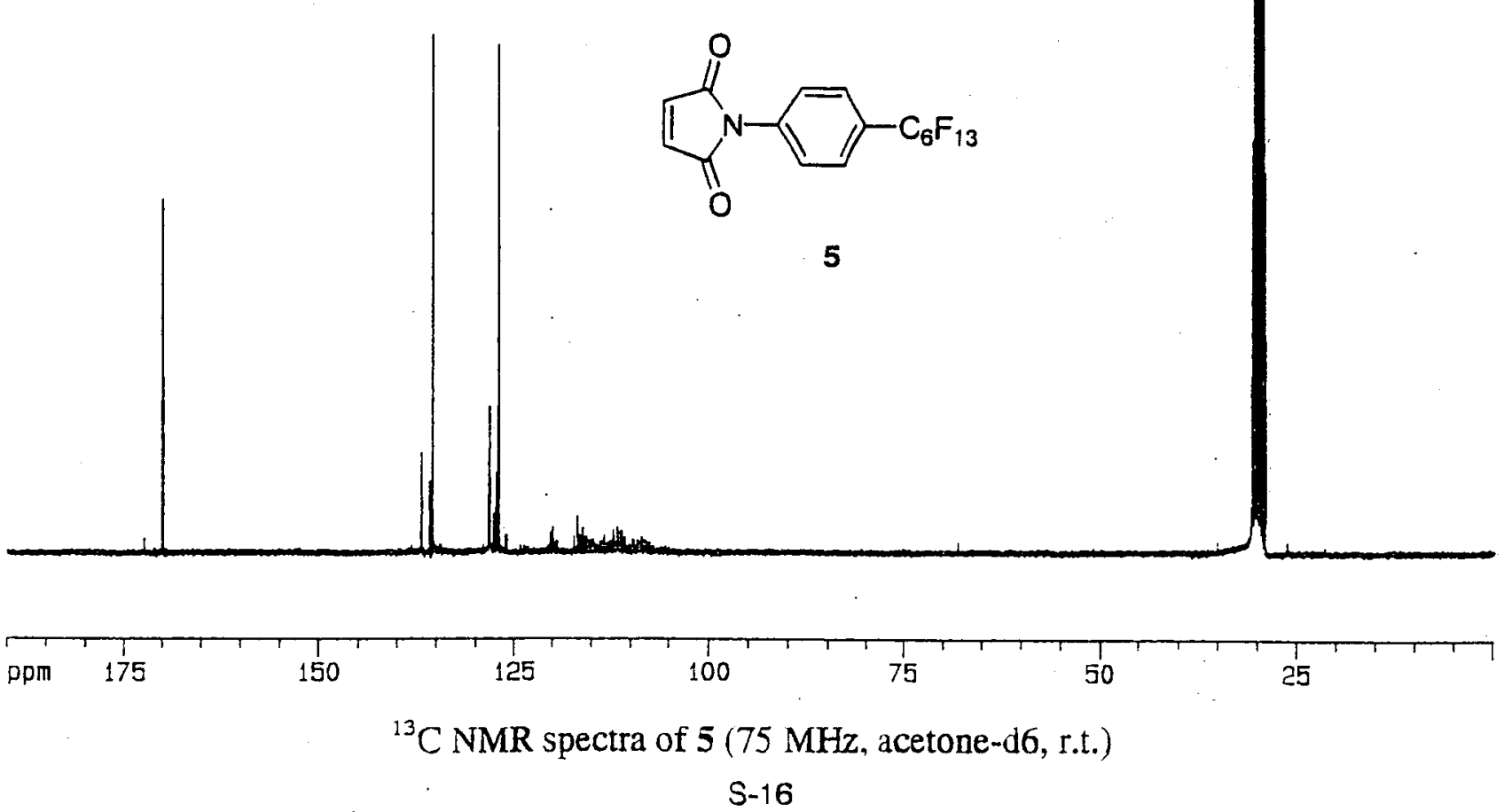
(C) 2003 American Chemical Society, Org. Lett., Werner ol035214a Supporting Info Page 4

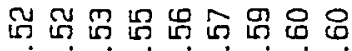
言 审审审审审审审审
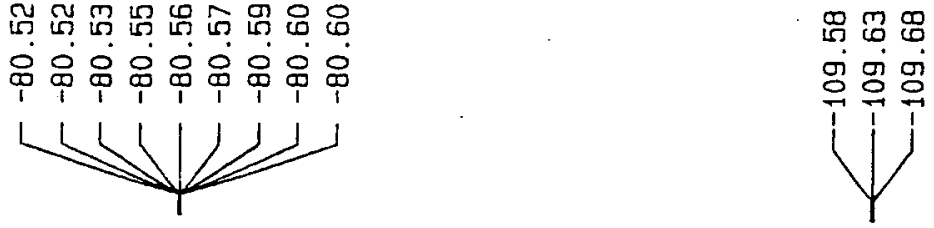

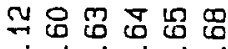

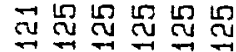
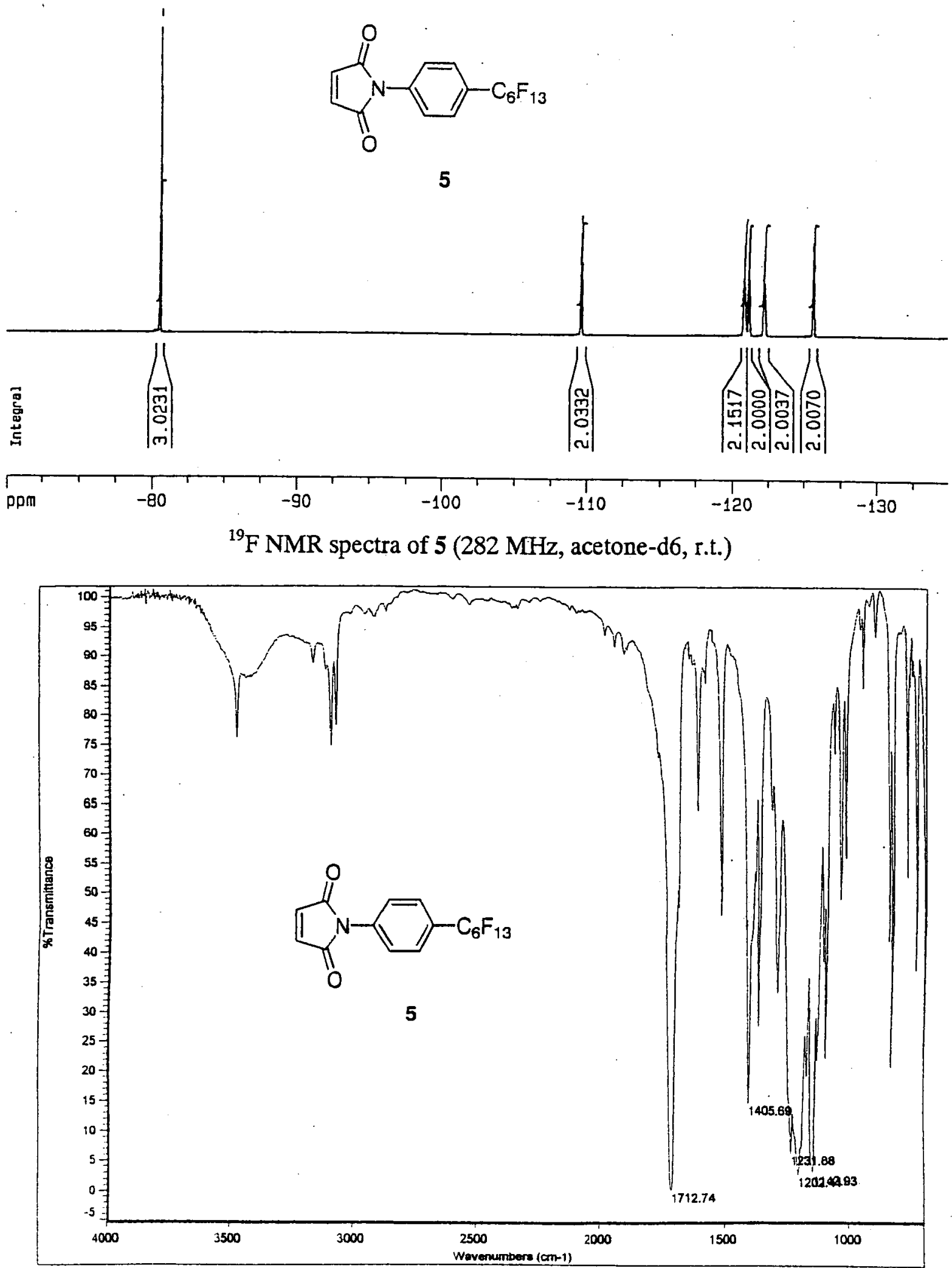

IR suectra of $5(\mathrm{KBr})$

S-17 
(C) 2003 American Chemical Society, Org. Lett., Werner ol035214a Supporting Info Page 5
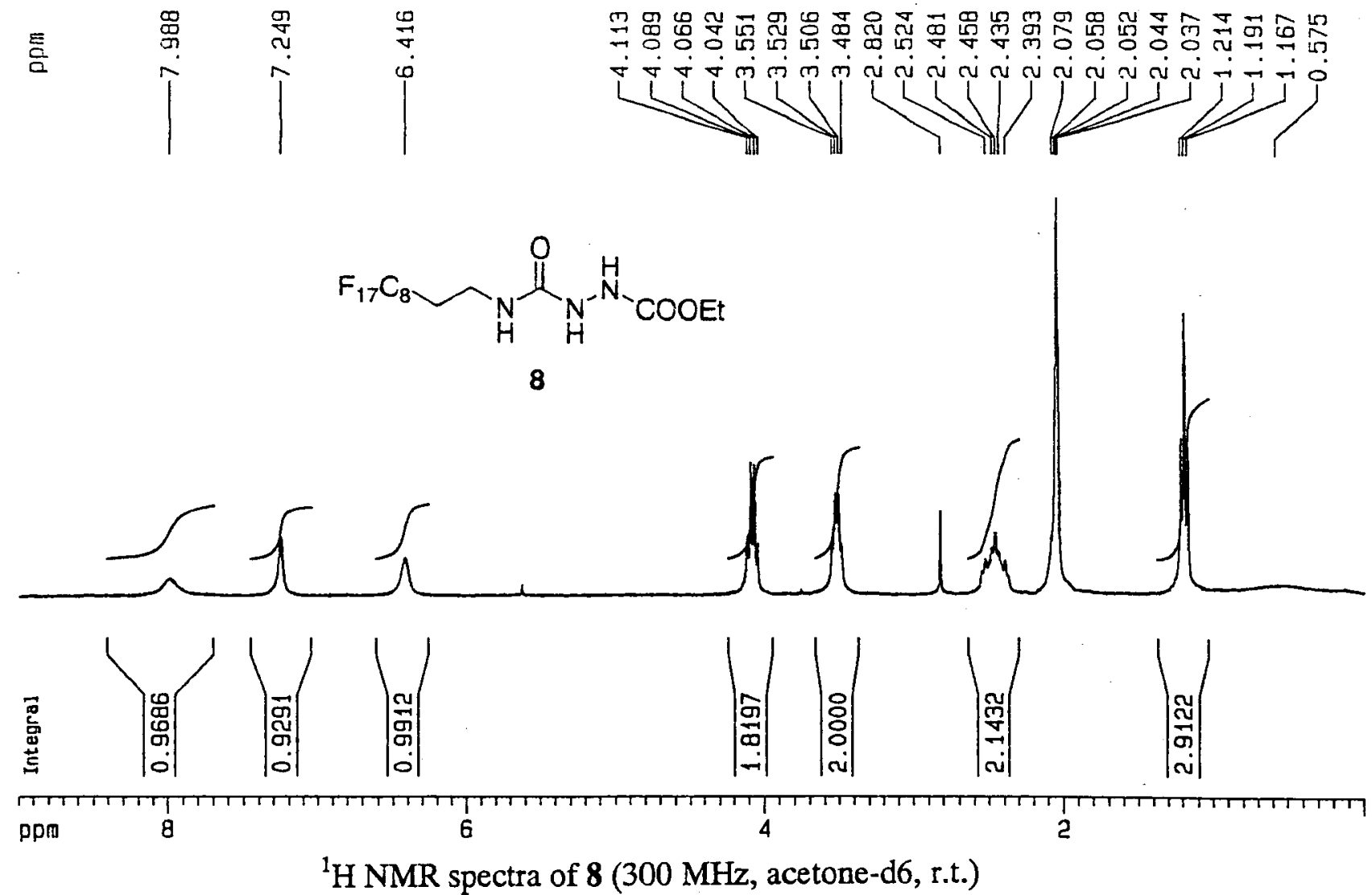

言

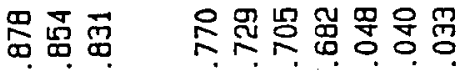

लं<smiles>O=c1[nH][nH]c(=O)n1CCCC(F)F</smiles>

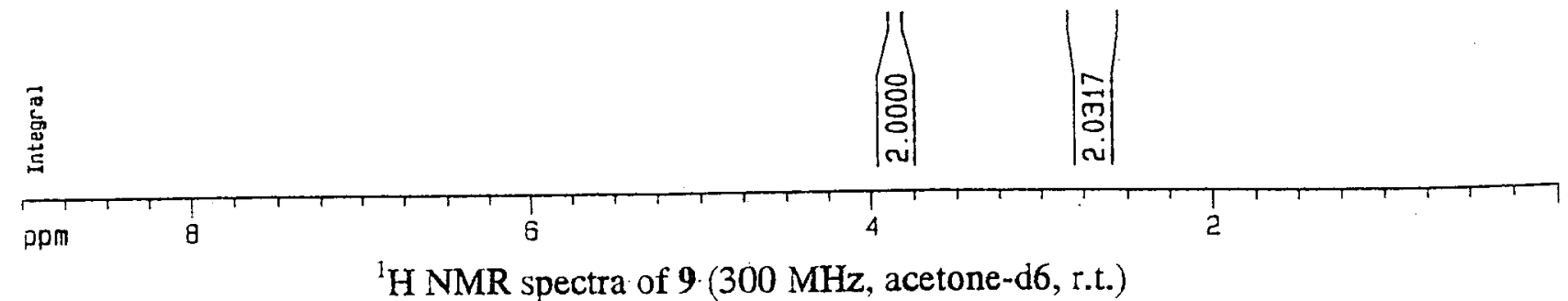


(C) 2003 American Chemical Society, Org. Lett., Werner ol035214a Supporting Info Page 6

통

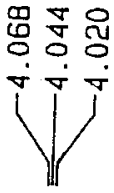

कิ

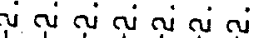<smiles>O=C1N=NC(=O)N1CCCBr</smiles>
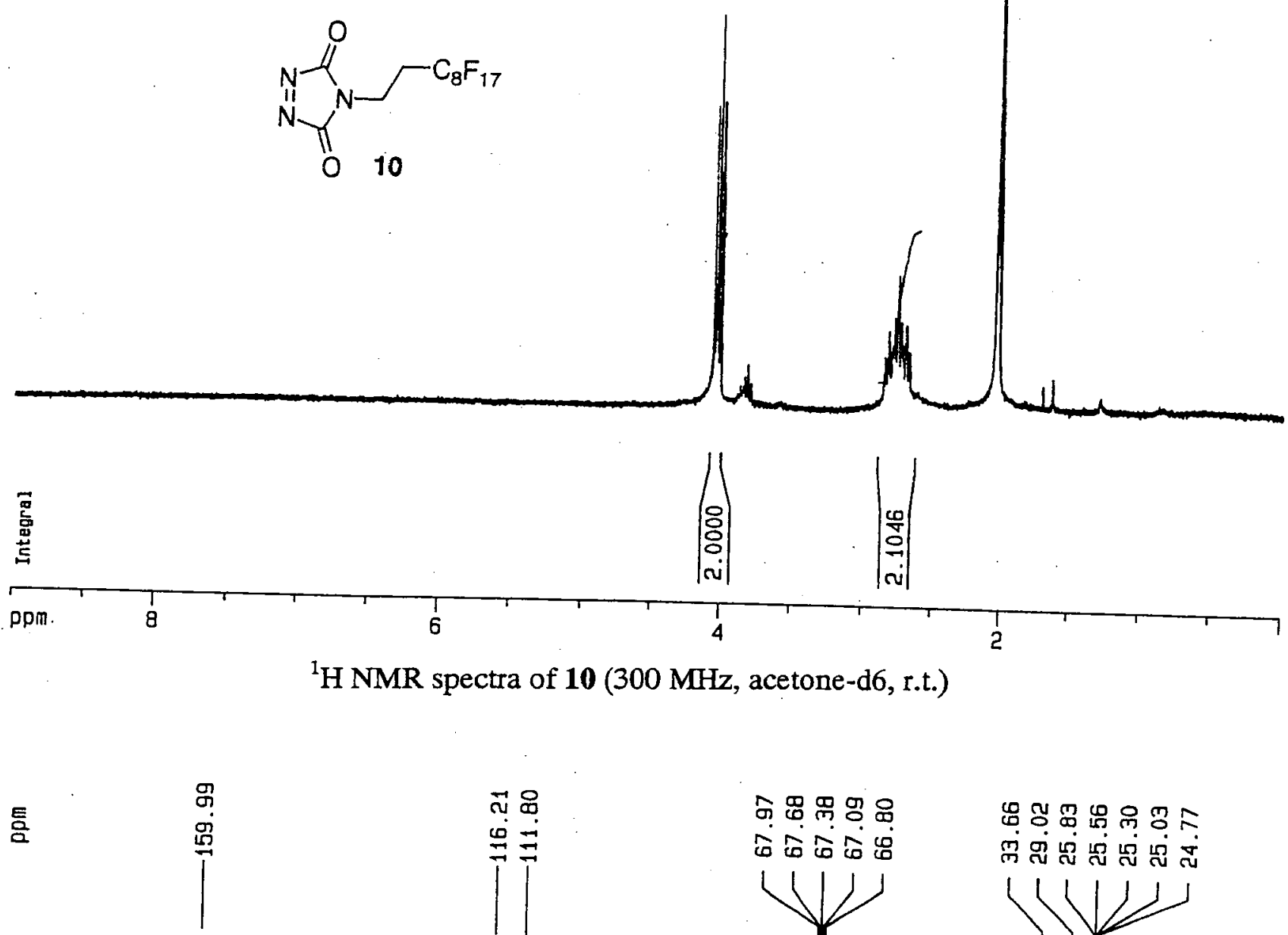

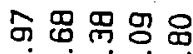
65 60 6

品 용品

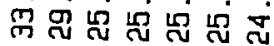
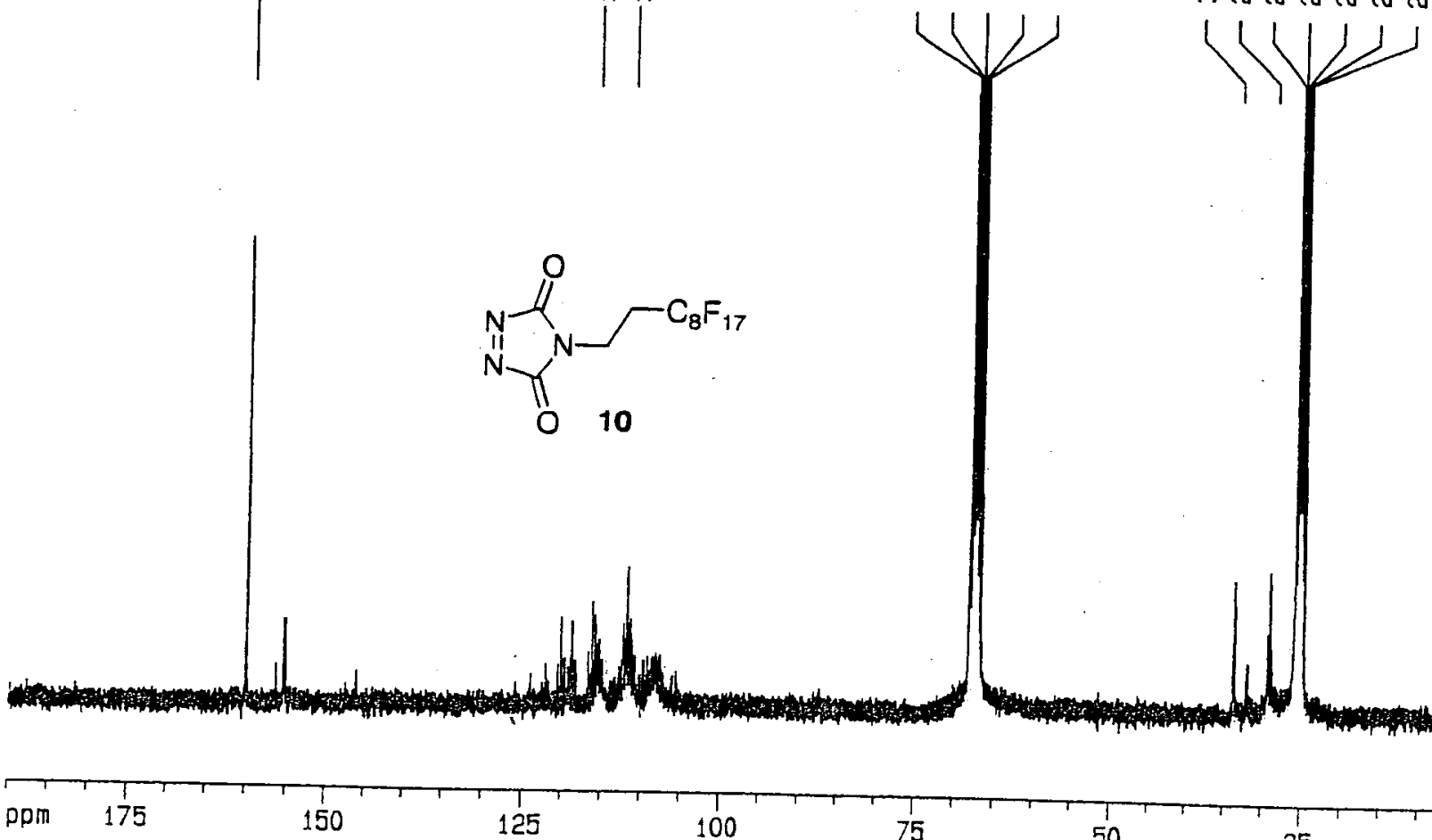

75
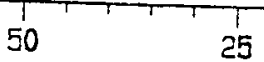

${ }^{13} \mathrm{C}$ NMR spectra of $10(75 \mathrm{MHz}$, thf-d8, r.t.)

S-19 
(C) 2003 American Chemical Society, Org. Lett., Werner ol035214a Supporting Info Page 7 㟧岕

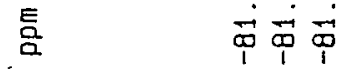
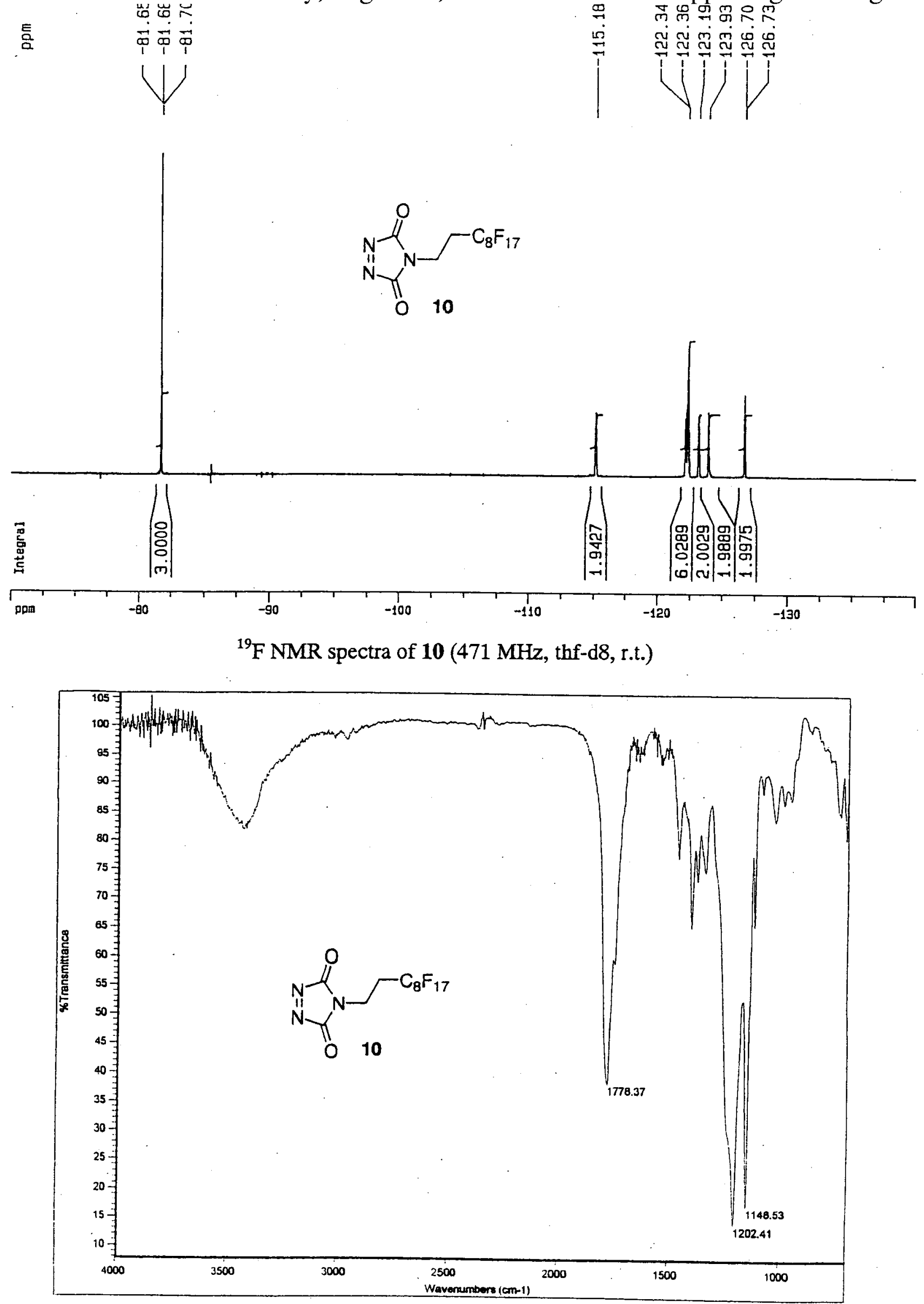

IR spectra of $10(\mathrm{KBr})$ 
(c) 2003 American Chemical Society, Org. Lett., Werner ol035214a Supporting Info Page 8
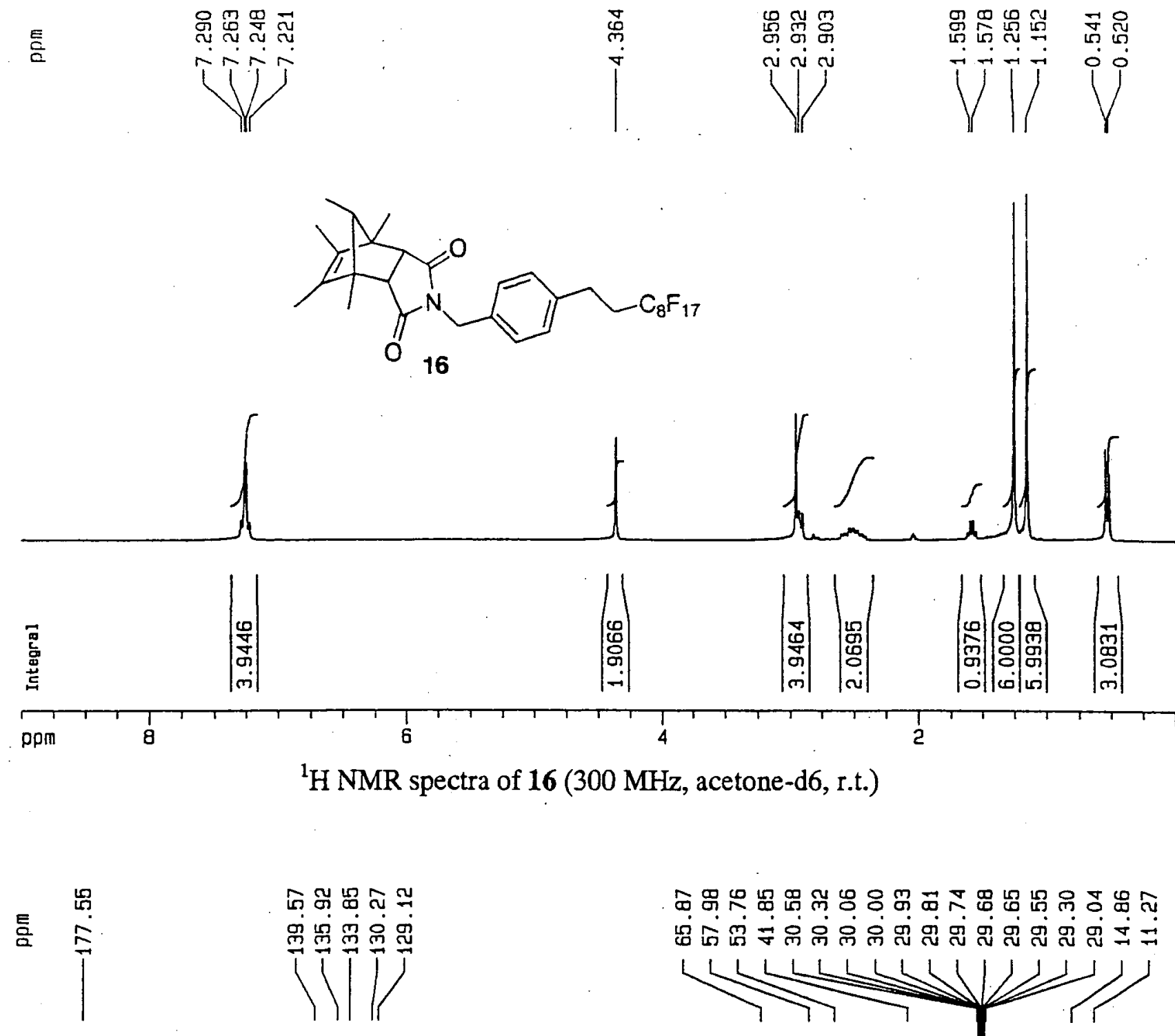

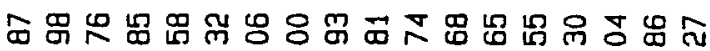

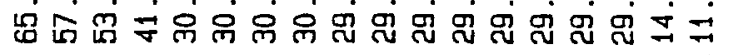
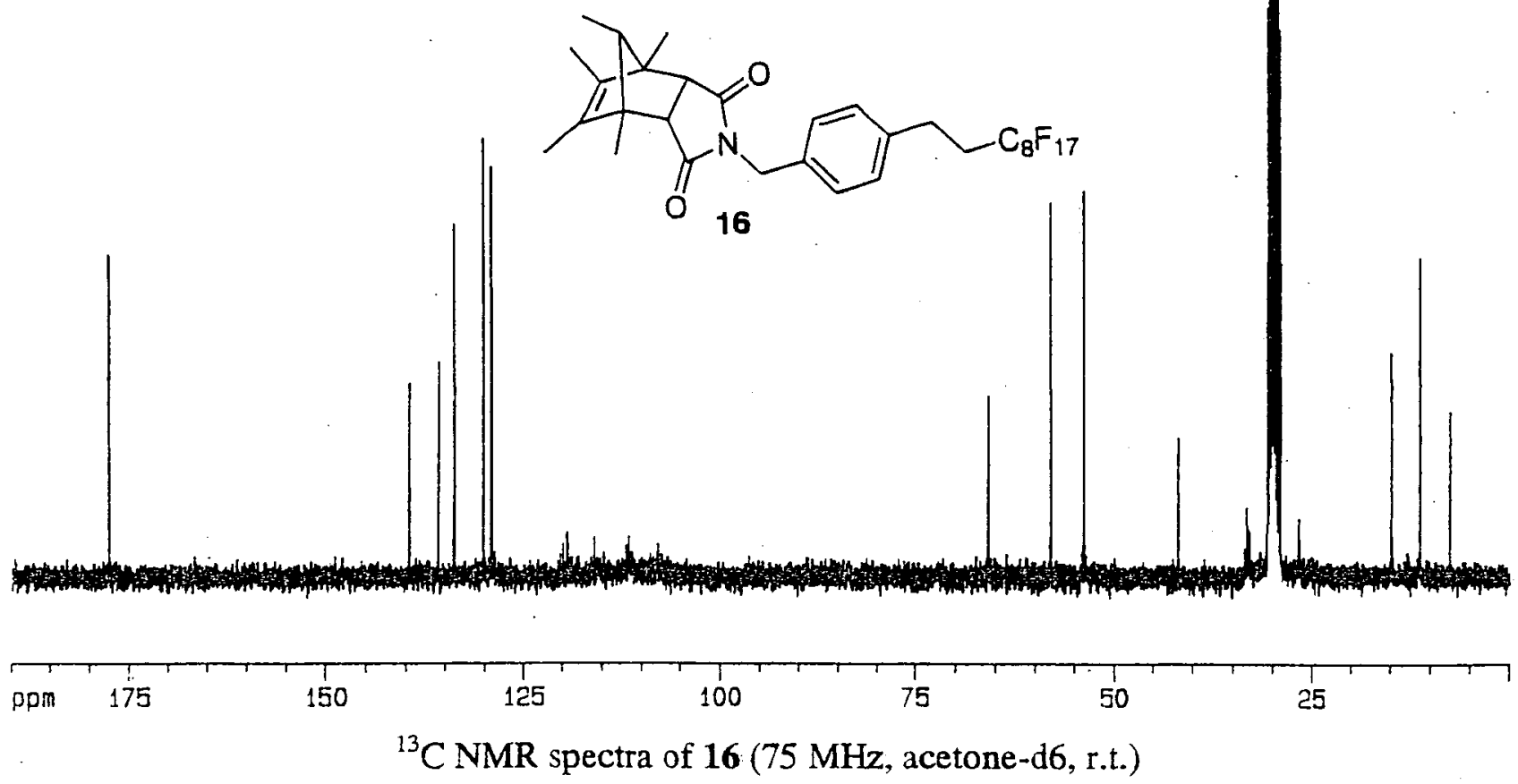
(C) 2003 American Chemical Society, Org. Lett., Werner ol035214a Supporting Info Page 9
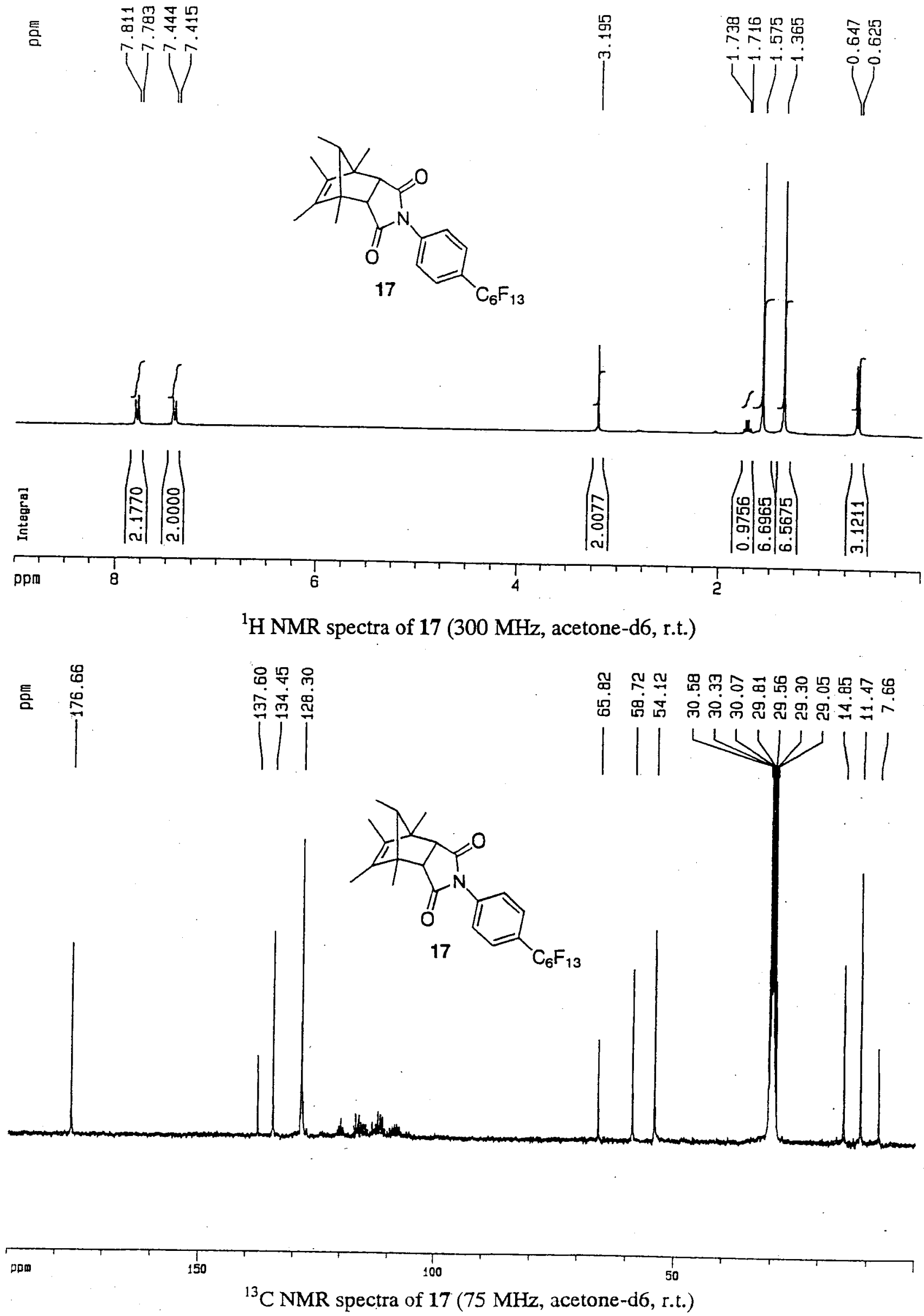
(c) 2003 American Chemical Society, Org. Lett., Werner ol035214a Supporting Info Page 10
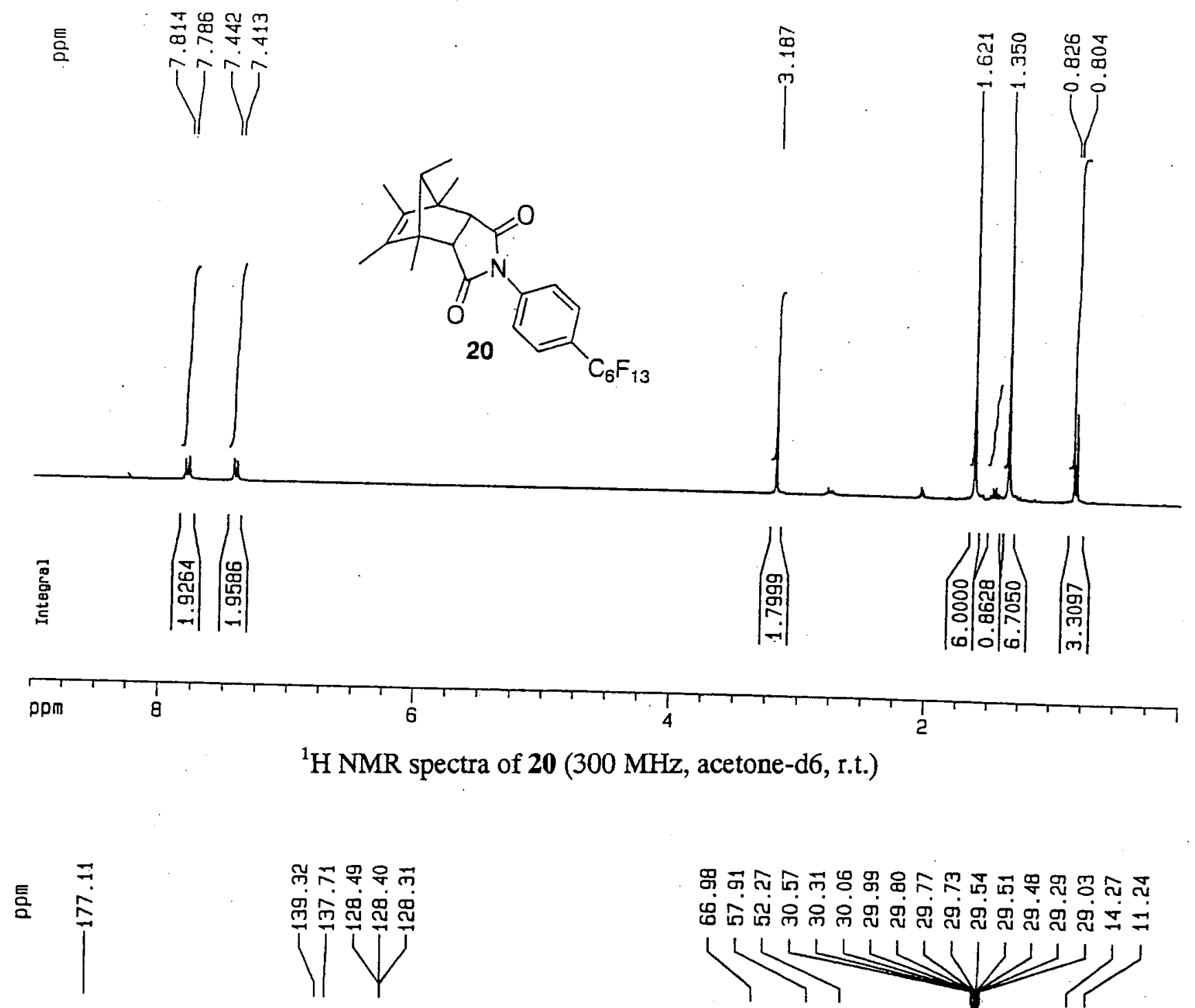
(C) 2003 American Chemical Society, Org. Lett., Werner ol035214a Supporting Info Page 11

틈

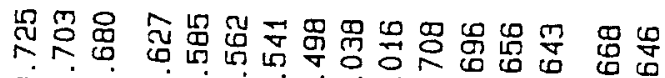
mं<smiles>CC1=C(C)C2(C)n3c(=O)n(CC[14CH2])c(=O)n3C1(C)C2(F)F</smiles>

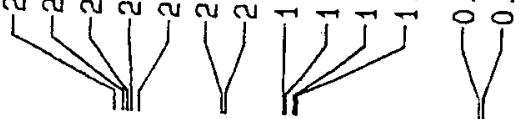

18

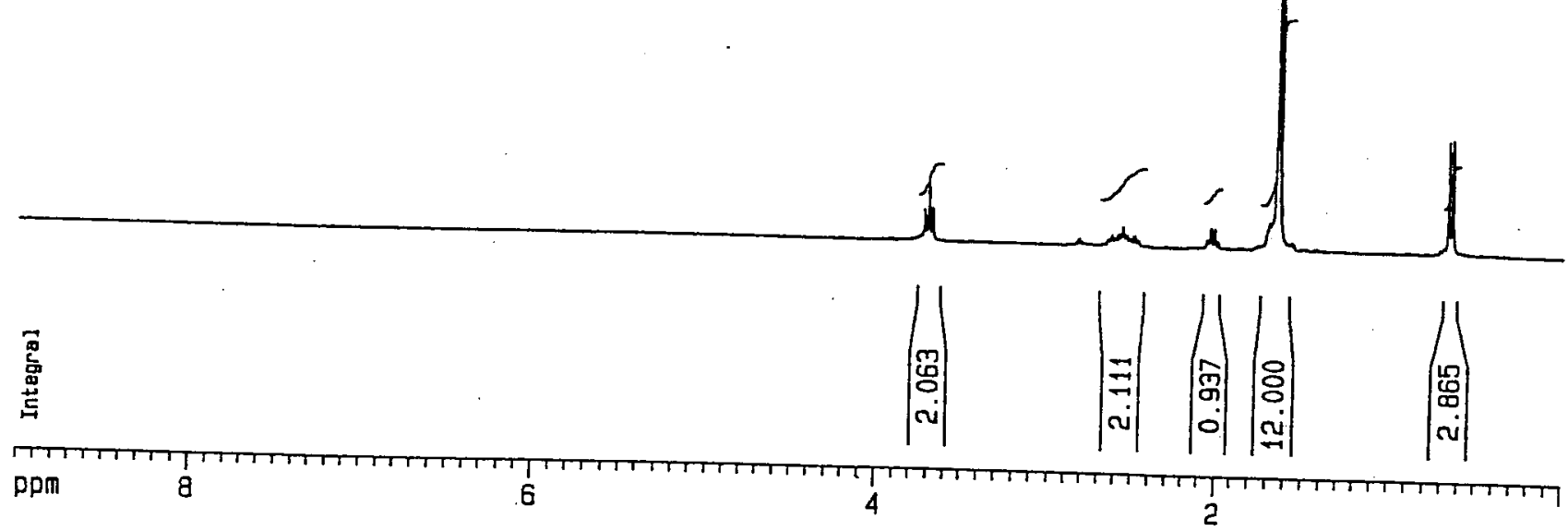

${ }^{1} \mathrm{H}$ NMR spectra of $18(300 \mathrm{MHz}$, acetone-d6, r.t.)
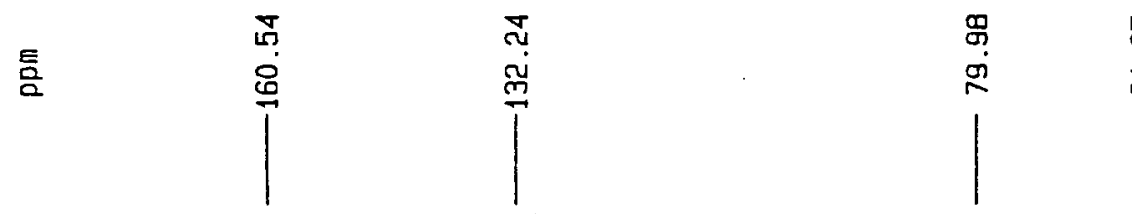

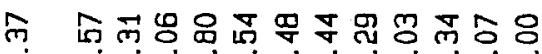

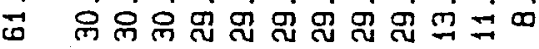
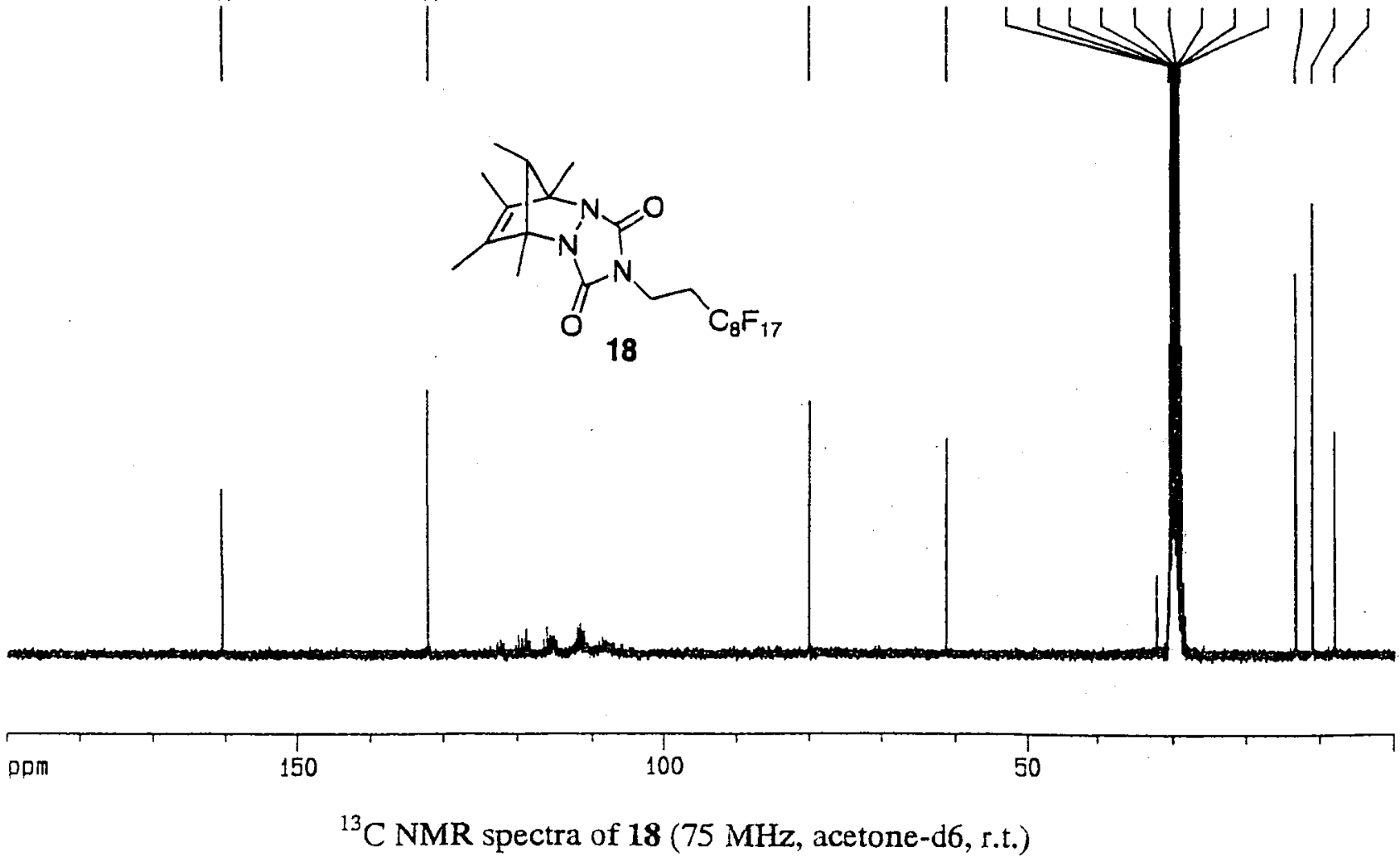
(c) 2003 American Chemical Society, Org. Lett., Werner ol035214a Supporting Info Page 12

틈
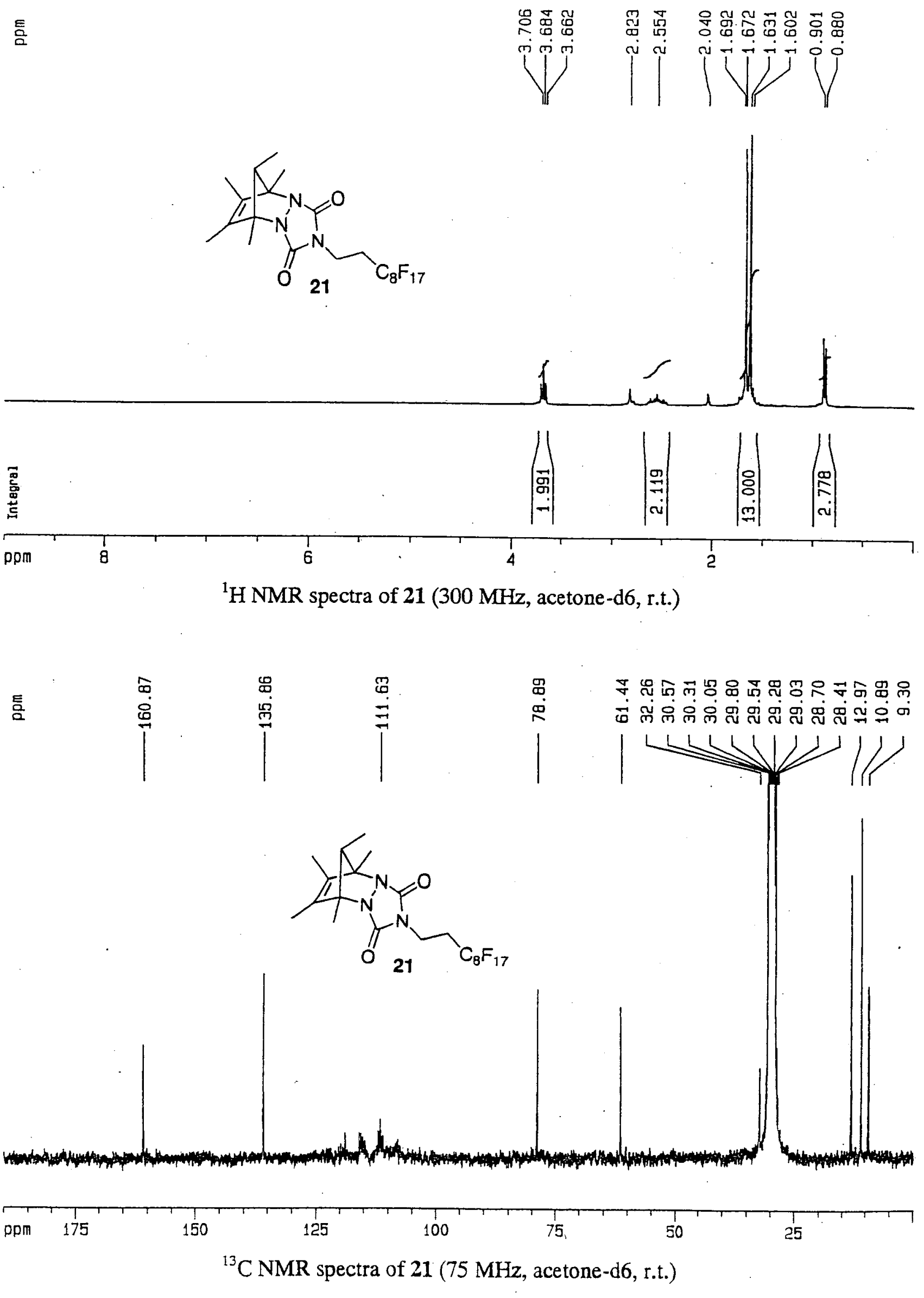
(c) 2003 American Chemical Society, Org. Lett., Werner ol035214a Supporting Info Page 13
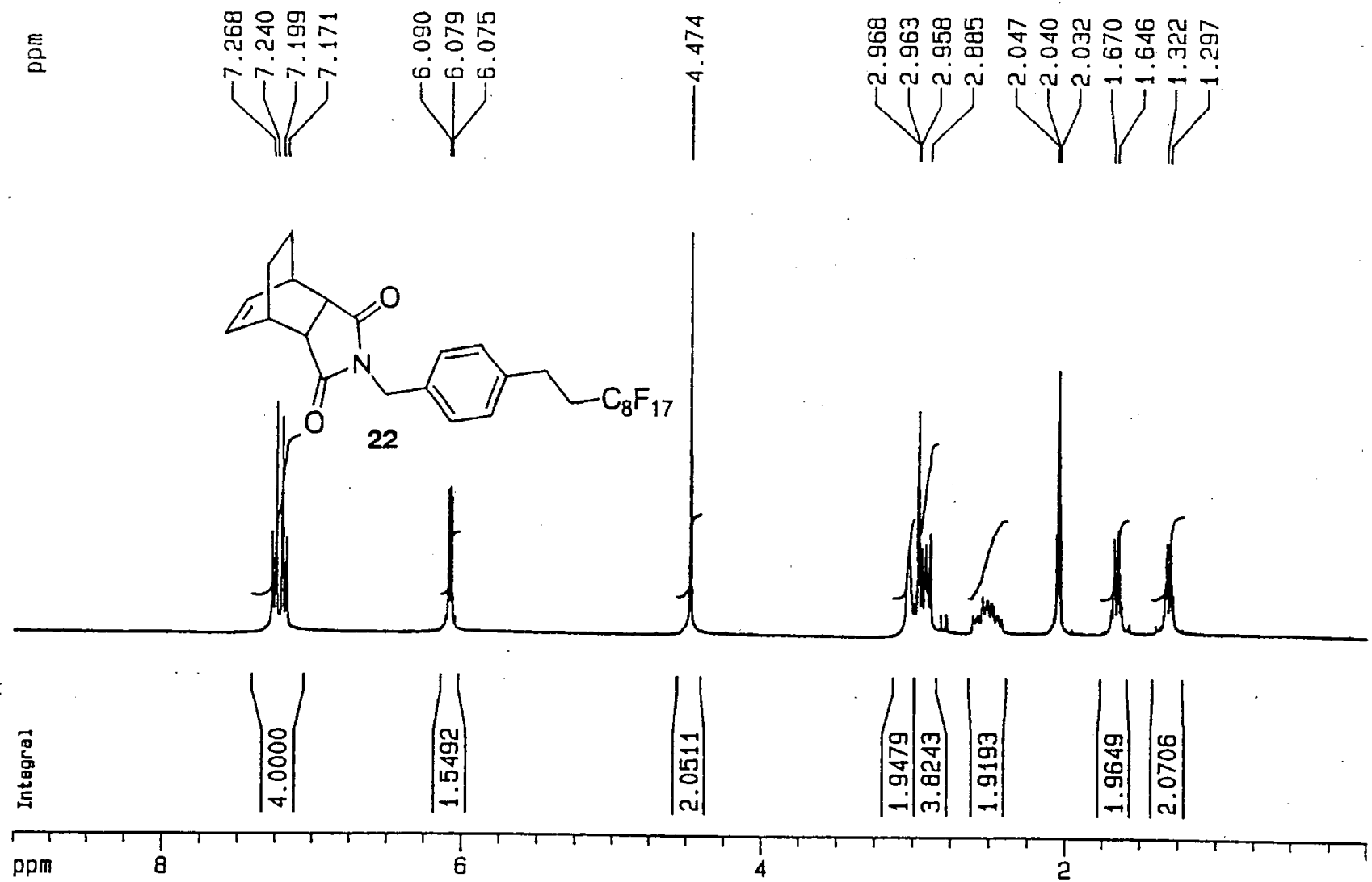

${ }^{1} \mathrm{H}$ NMR spectra of $22(300 \mathrm{MHz}$, acetone-d6, r.t.)

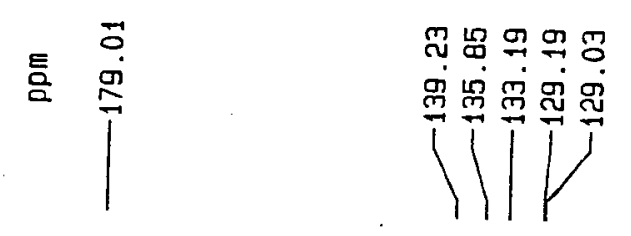

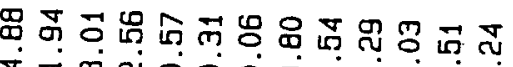

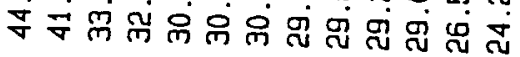
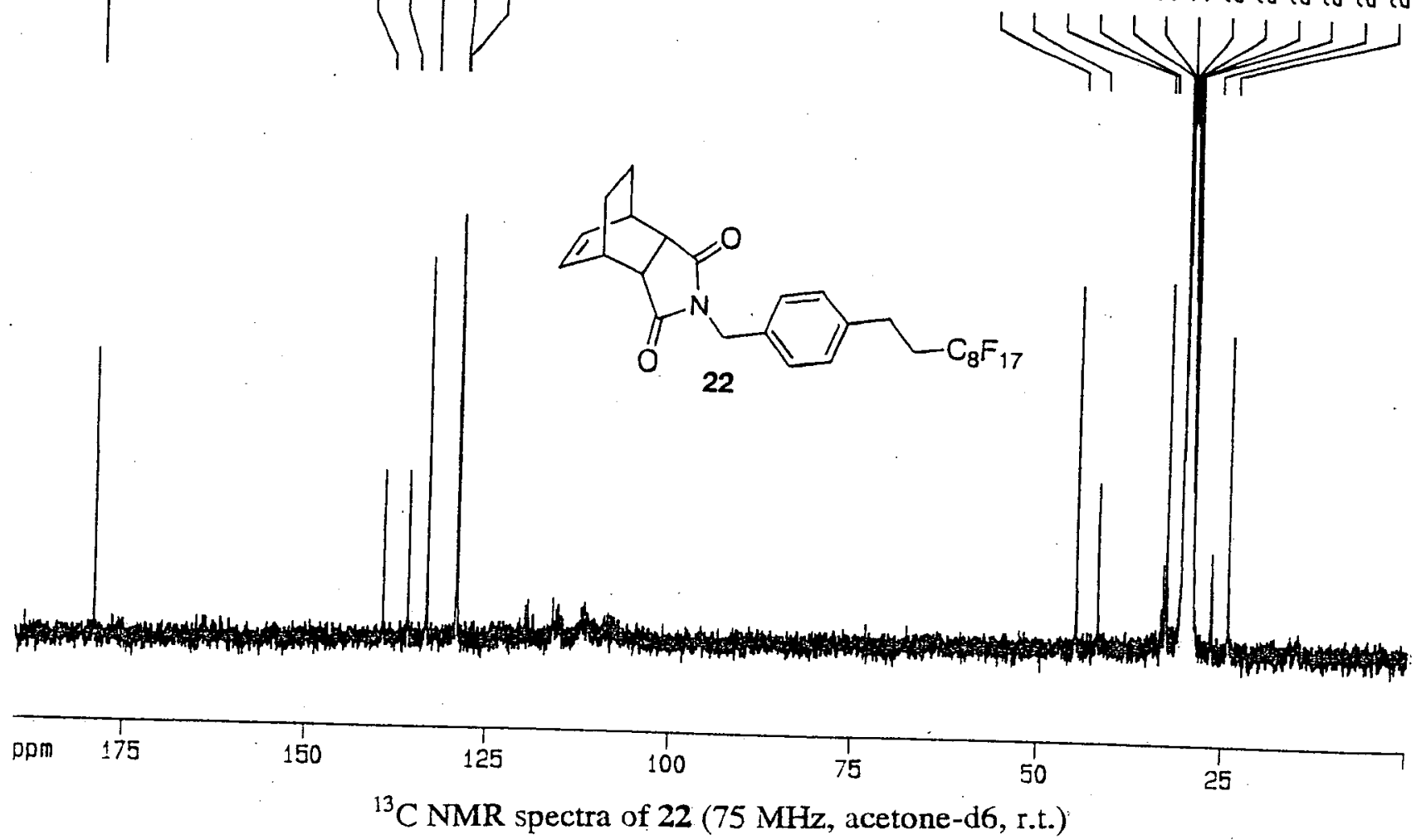
(c) 2003 American Chemical Society, Org. Lett., Werner ol035214a Supporting Info Page 14
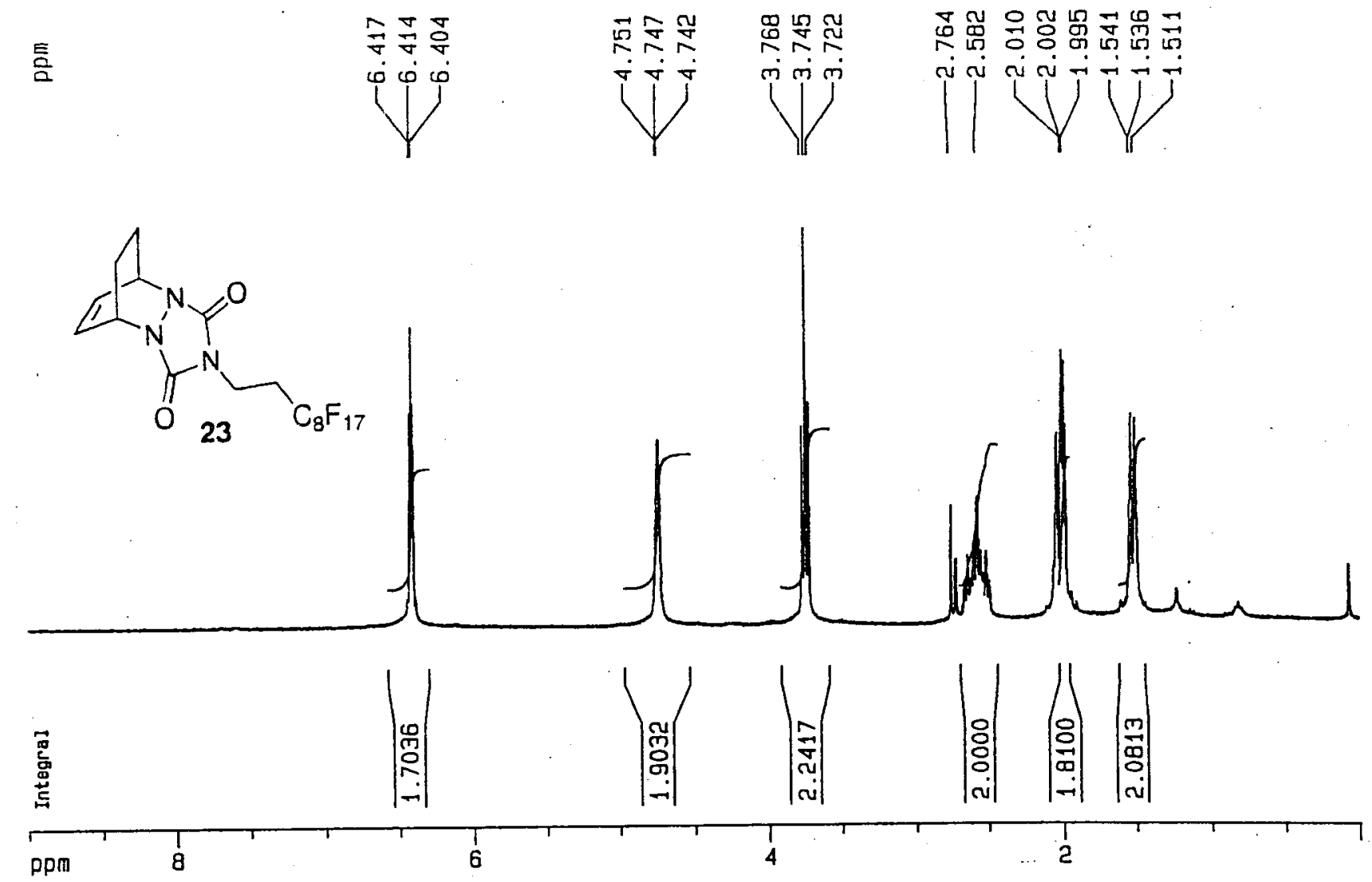

${ }^{1} \mathrm{H}$ NMR spectra of 23 (300 MHz, acetone-d6, r.t.)

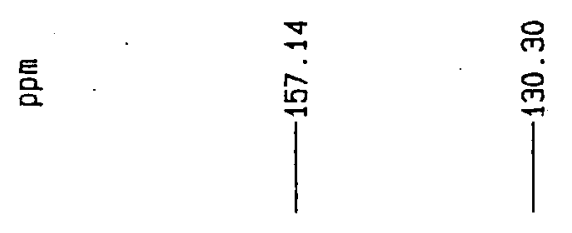

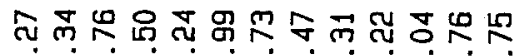

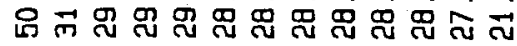
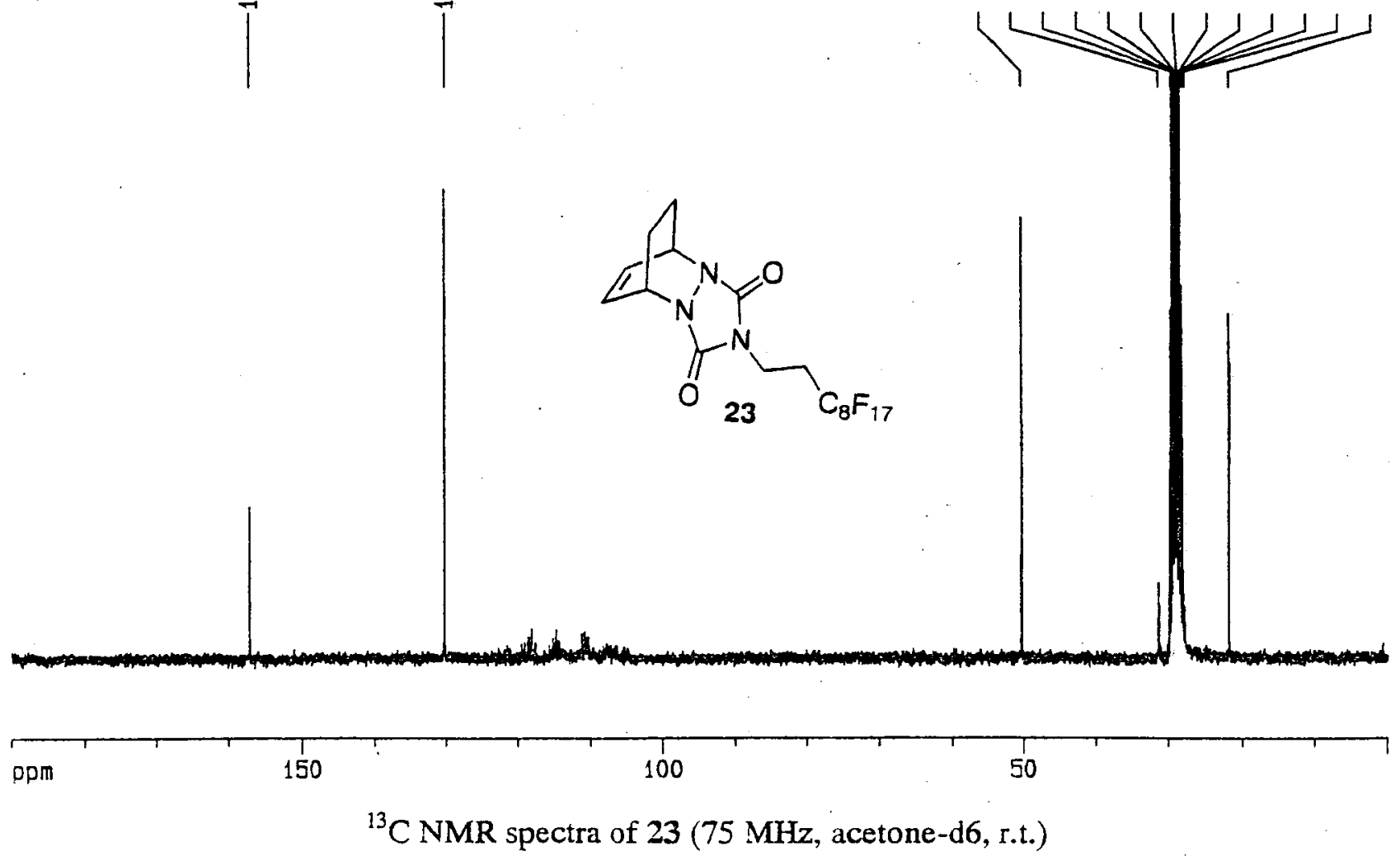
(C) 2003 American Chemical Society, Org. Lett., Werner ol035214a Supporting Info Page 15
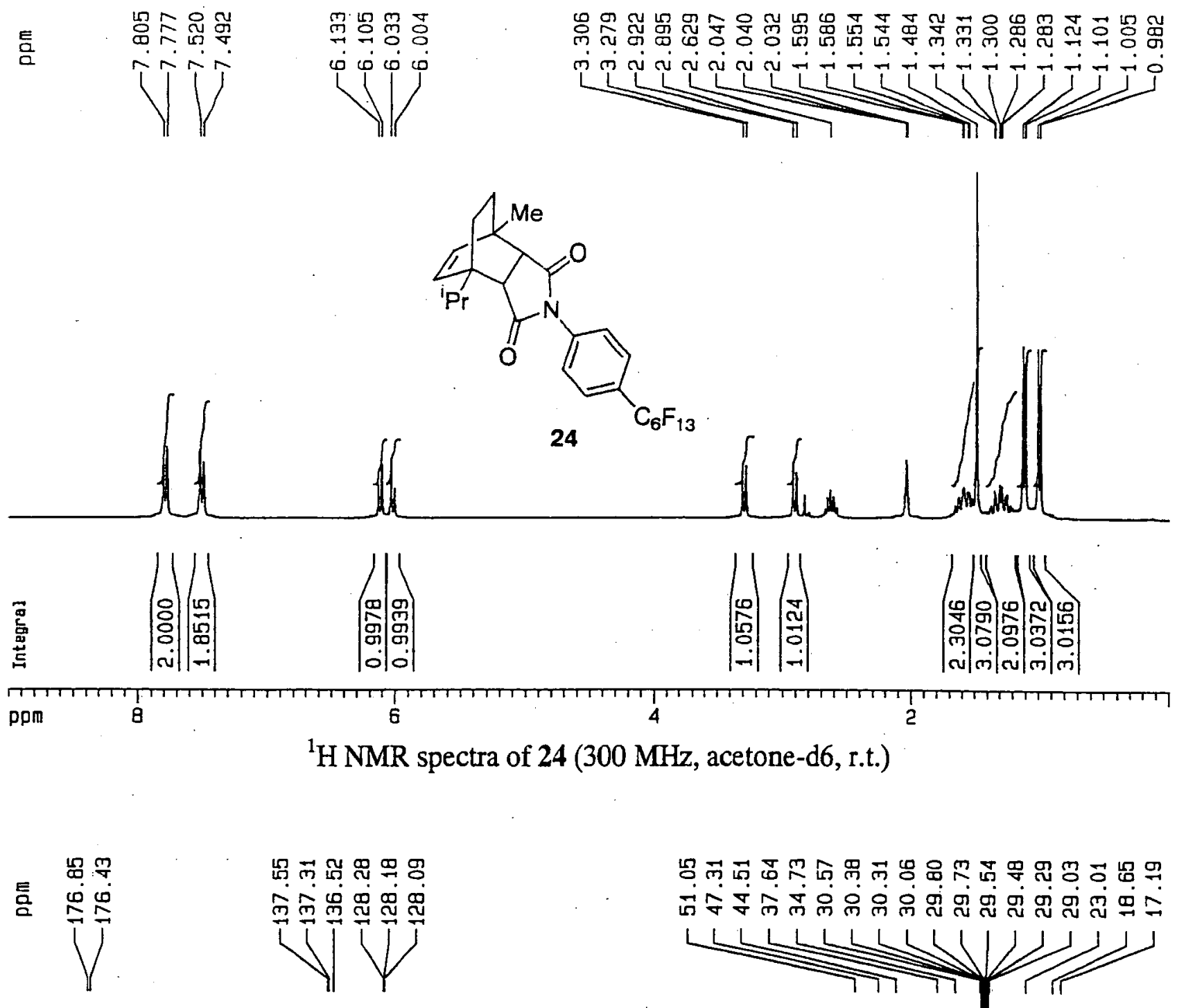

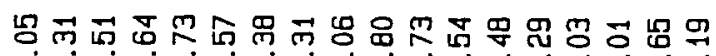

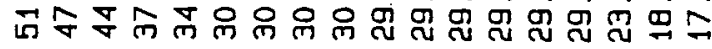
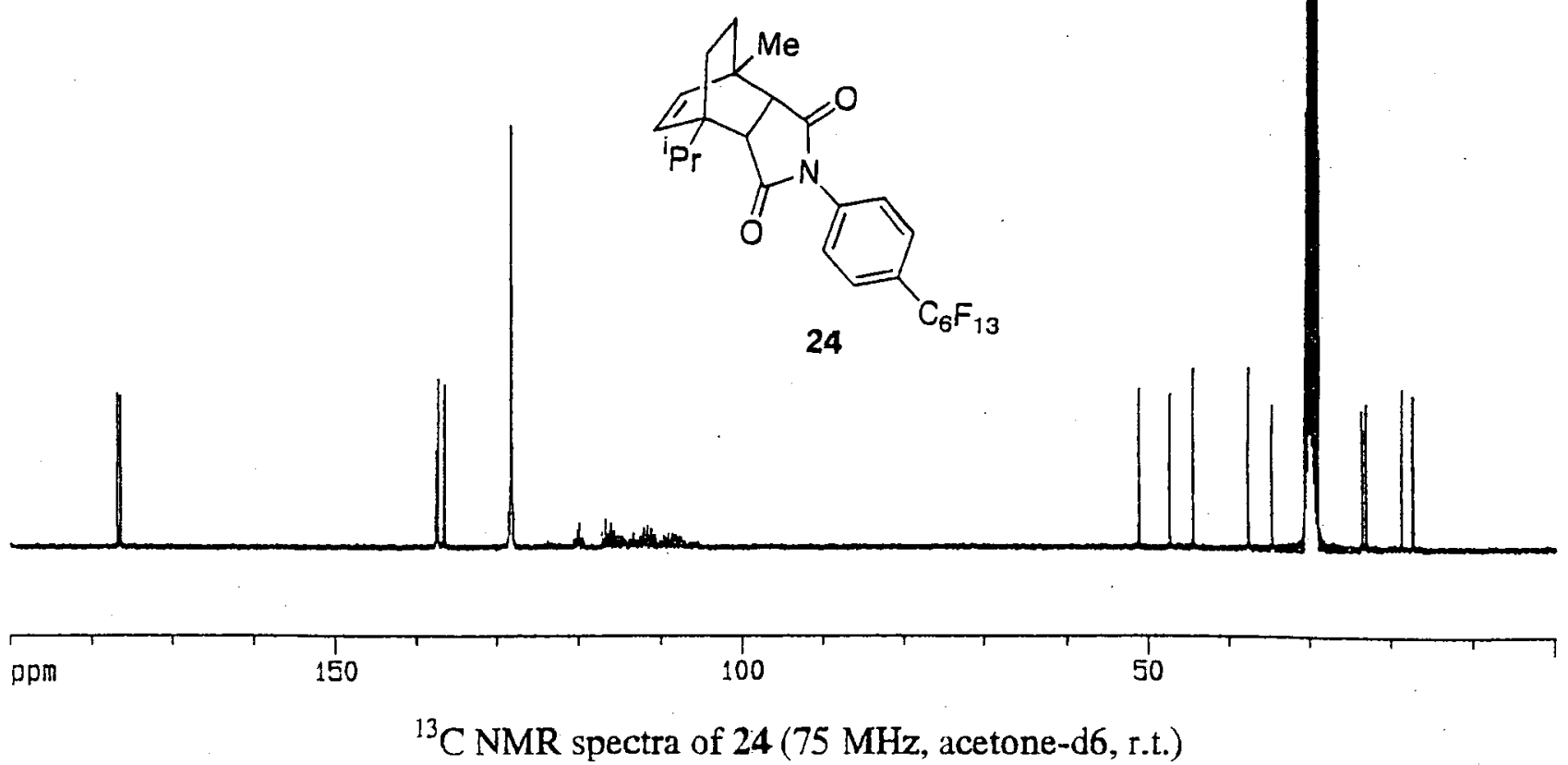
(C) 2003 American Chemical Society, Org. Lett., Werner ol035214a Supporting Info Page 16
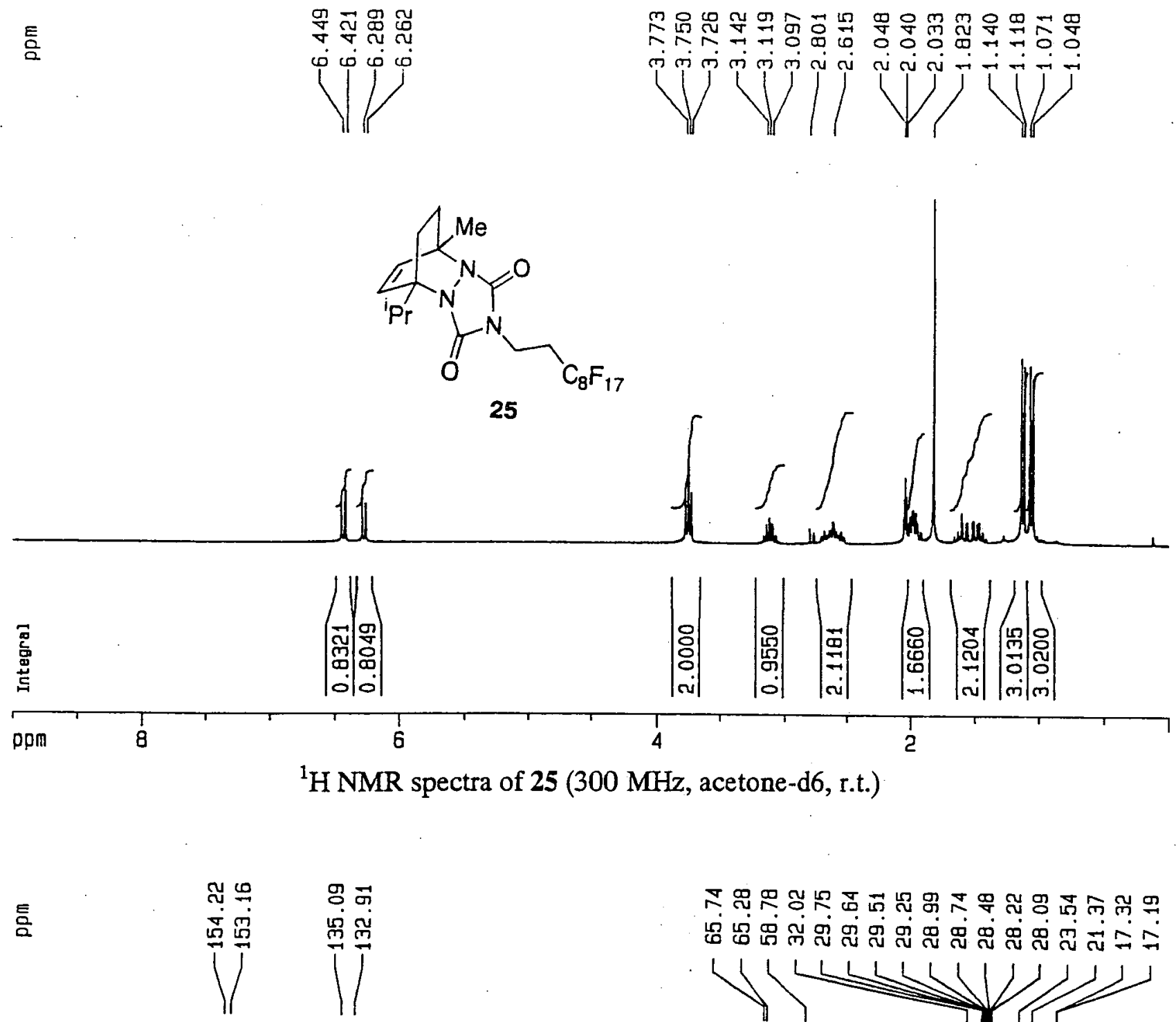

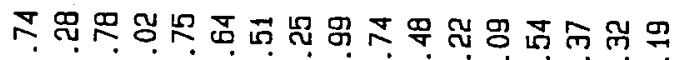

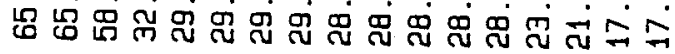
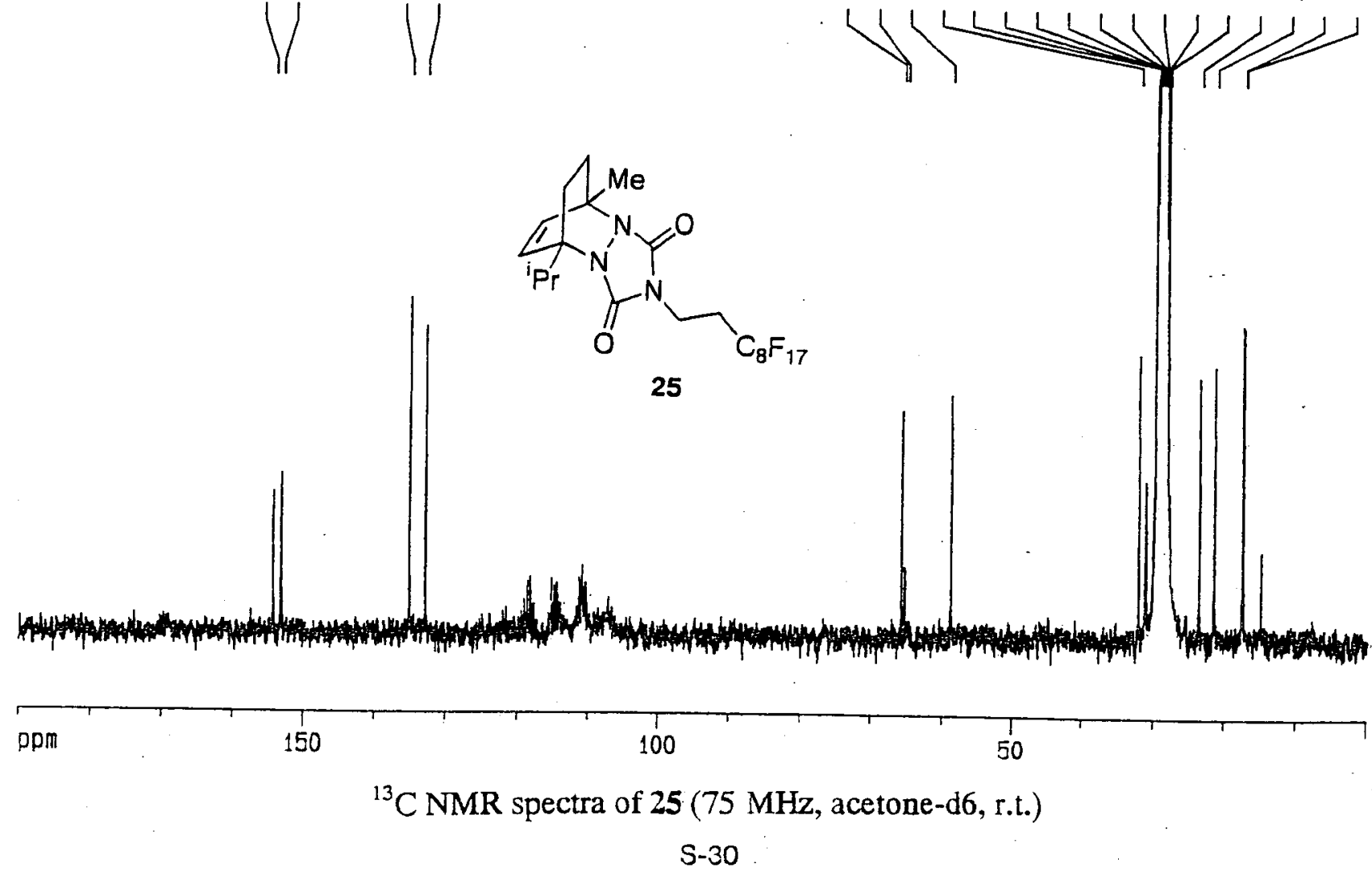
(C) 2003 American Chemical Society, Org. Lett., Werner ol035214a Supporting Info Page 17
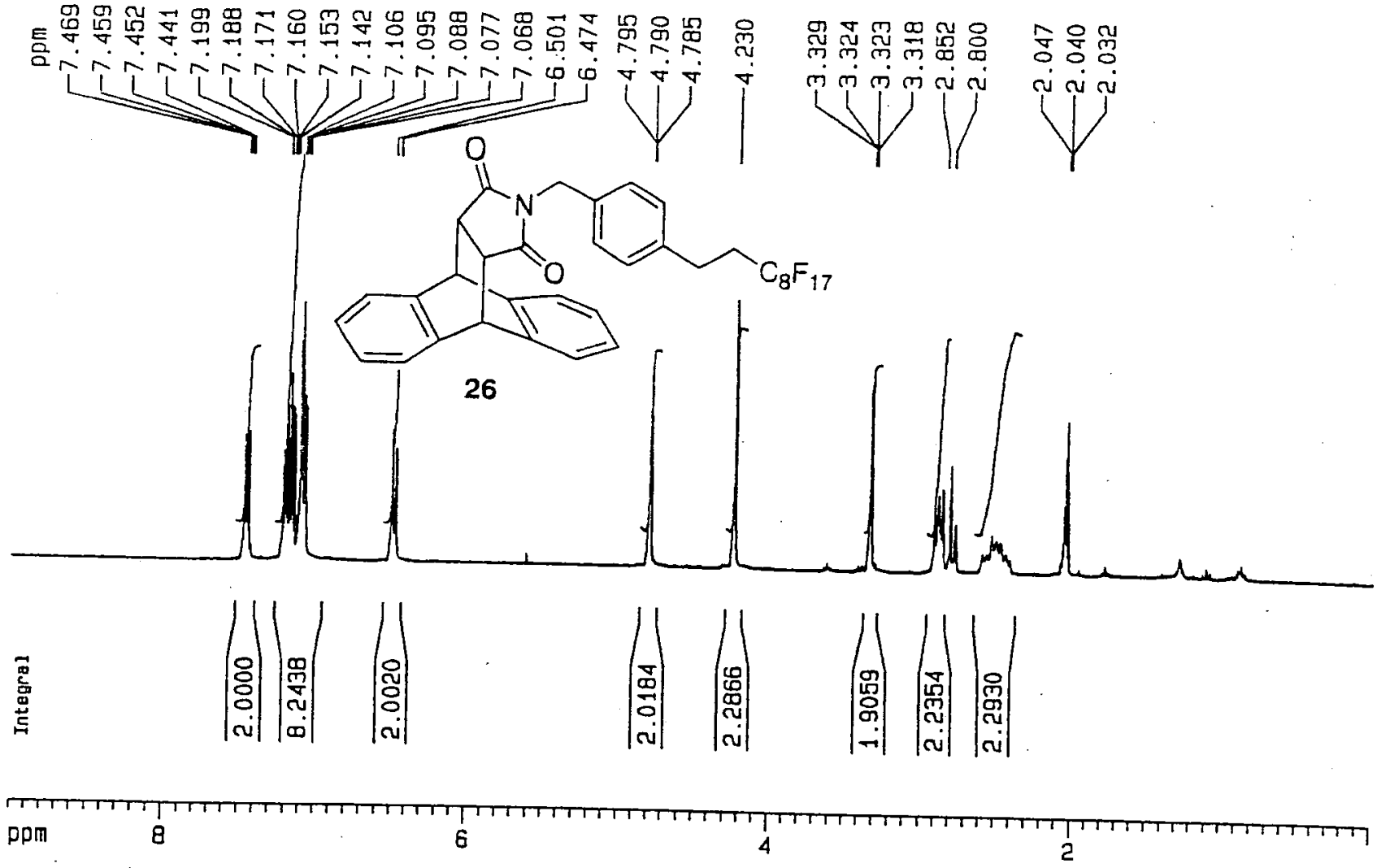

${ }^{1} \mathrm{H}$ NMR spectra of 26 (300 MHz, acetone-d6, r.t.)

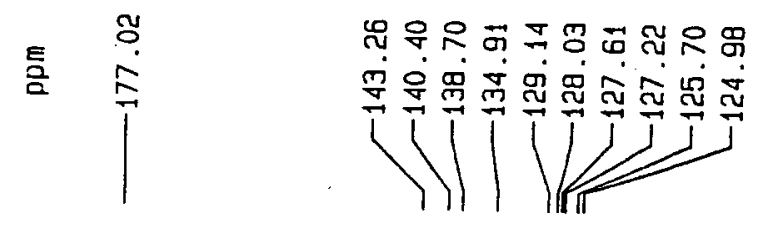

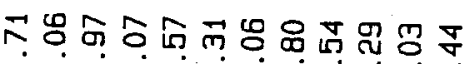

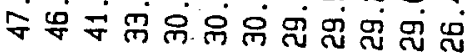

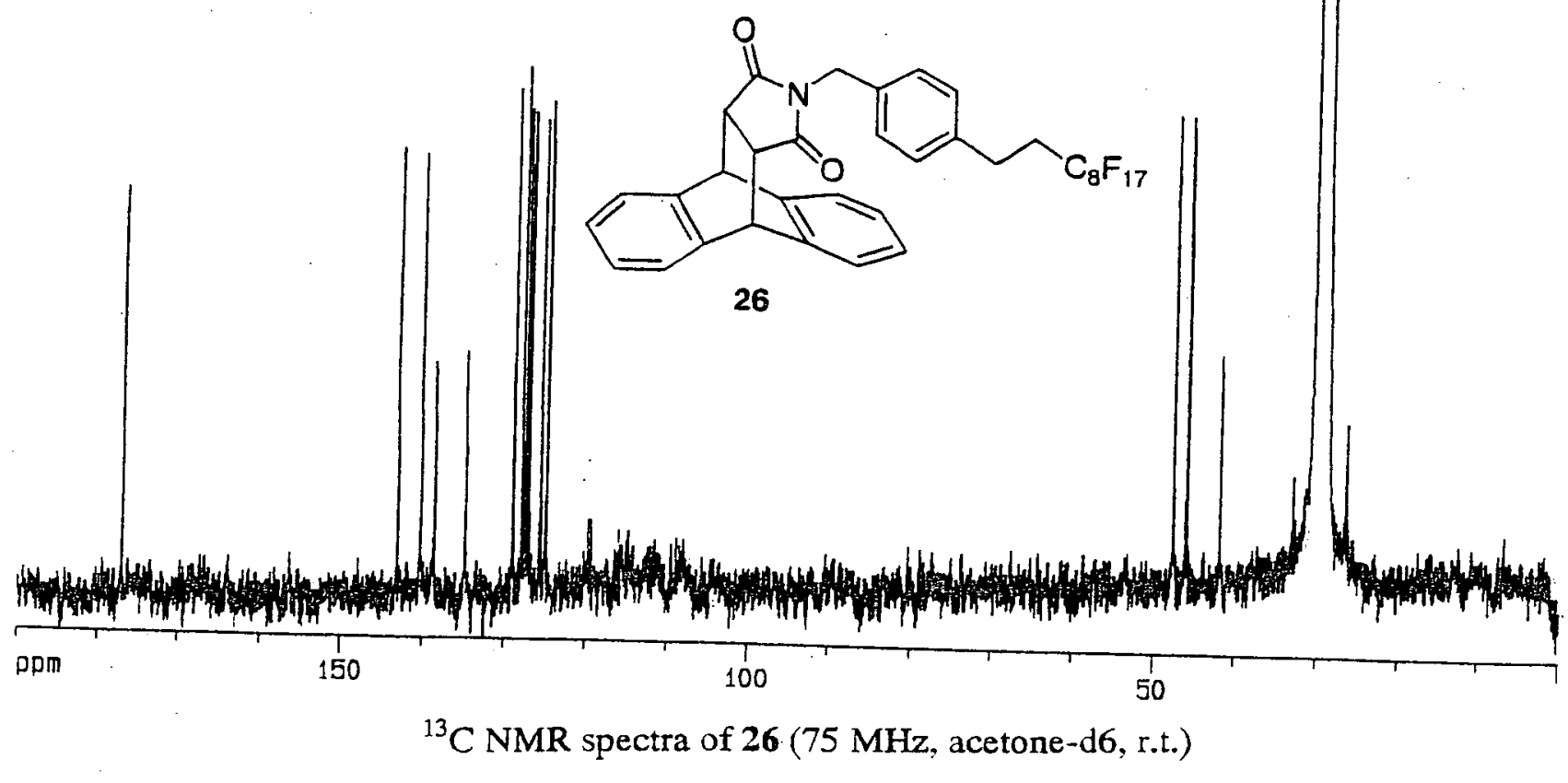


(c) 2003 American Chemical Society, Org. Lett., Werner ol035214a Supporting Info Page 18
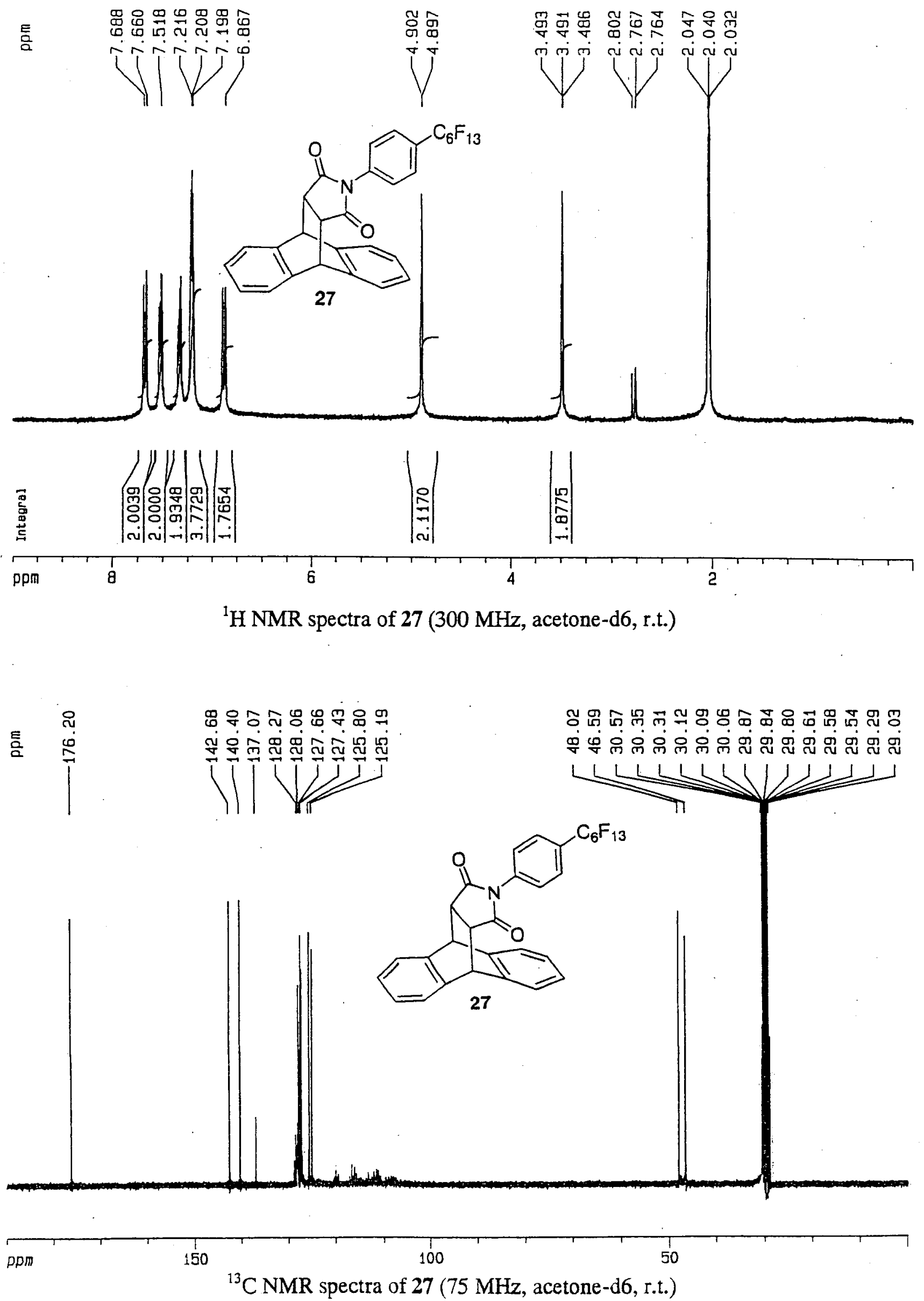

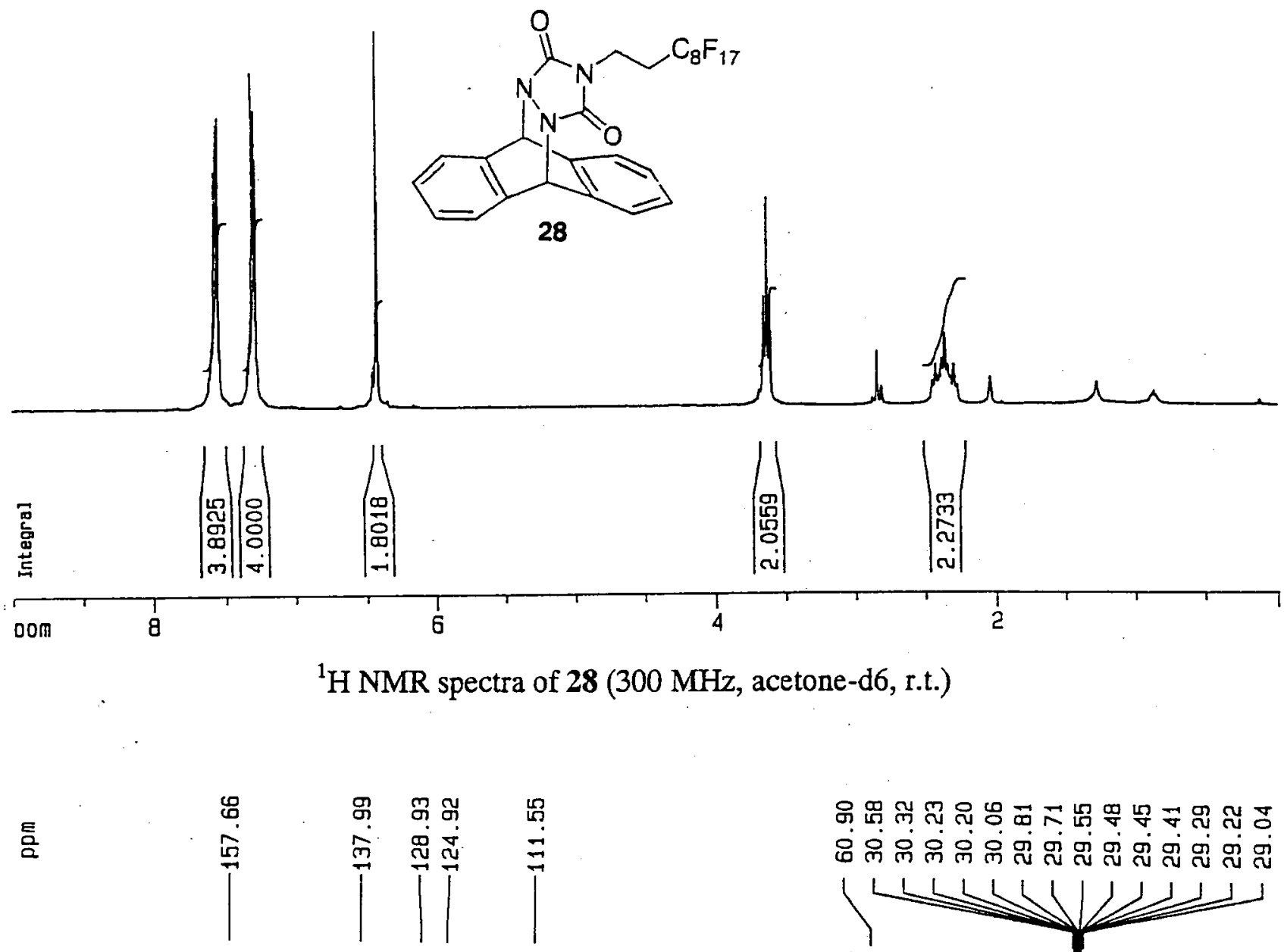

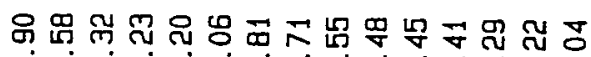

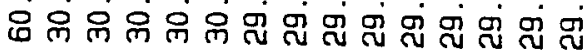
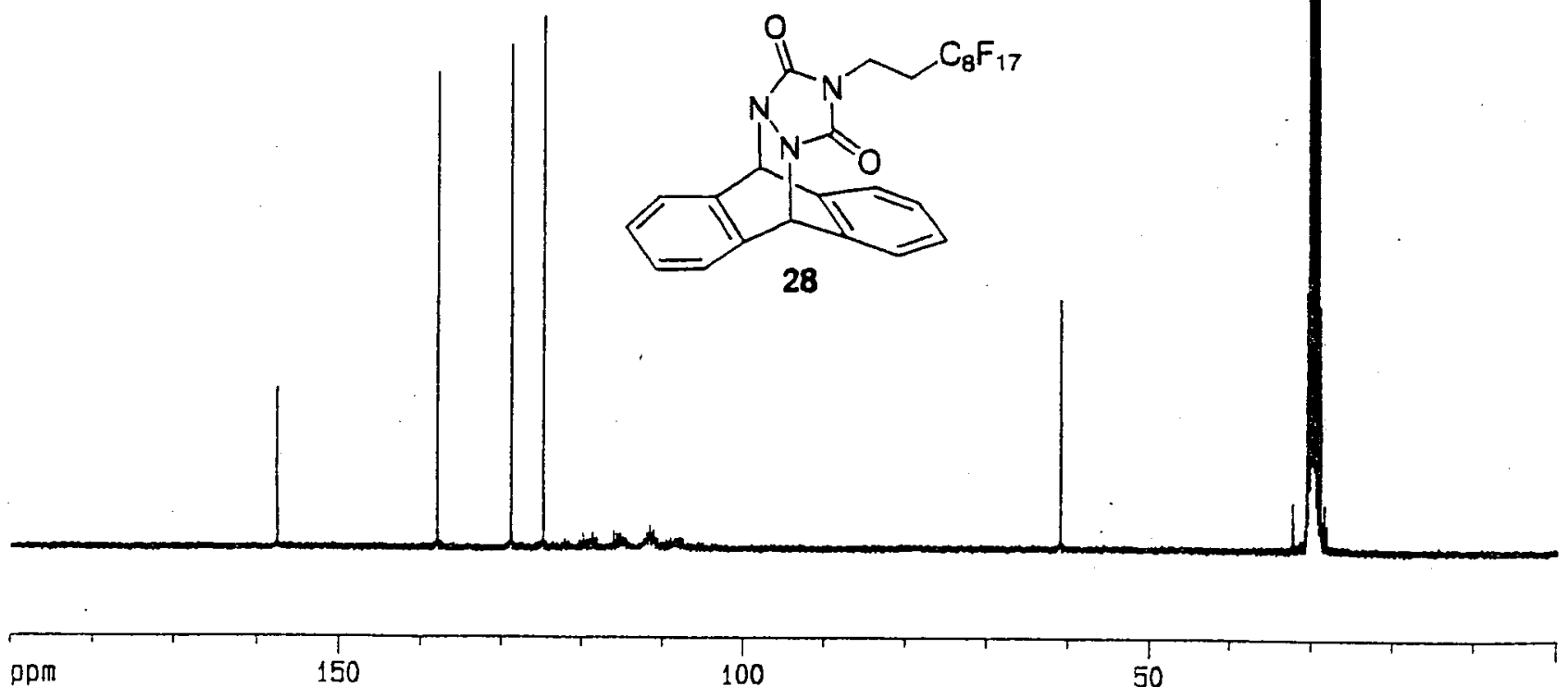

${ }^{13} \mathrm{C}$ NMR spectra of 28 (75 $\mathrm{MHz}$, acetone-d6, r.t.) 

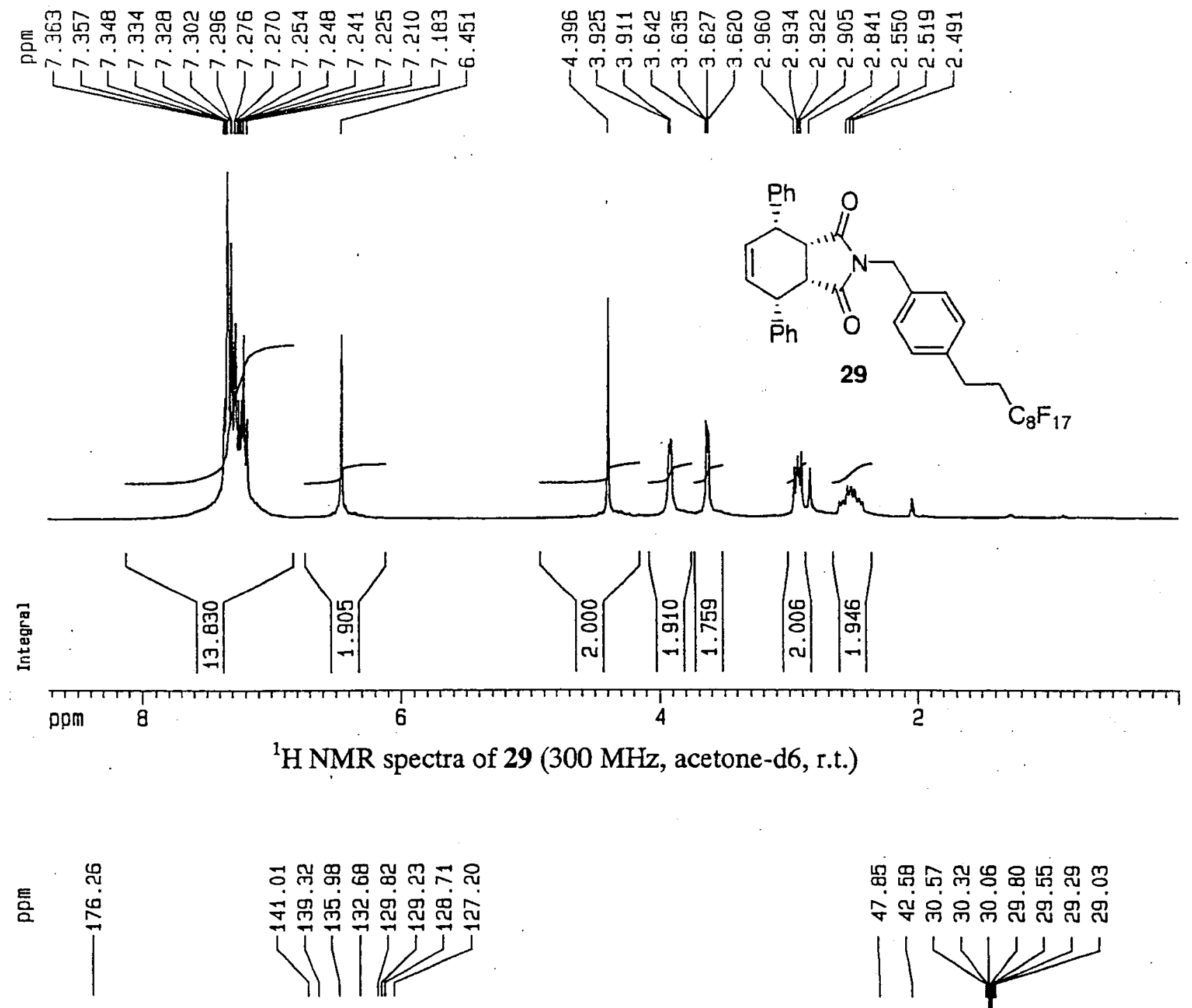

思罢的赑电品品思

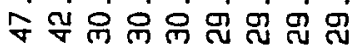
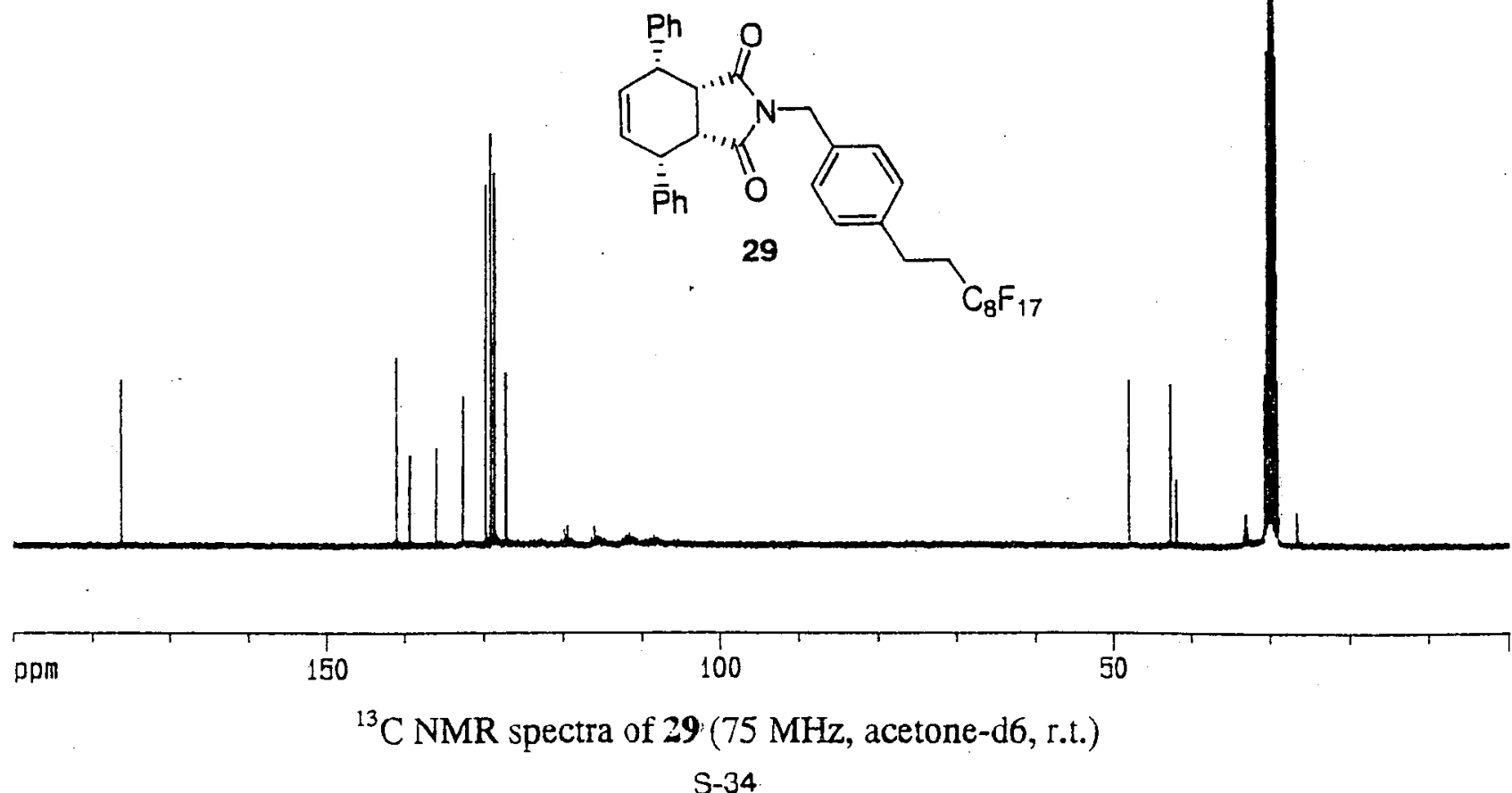


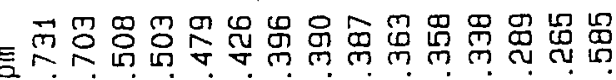

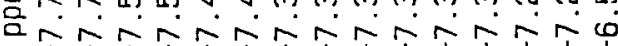
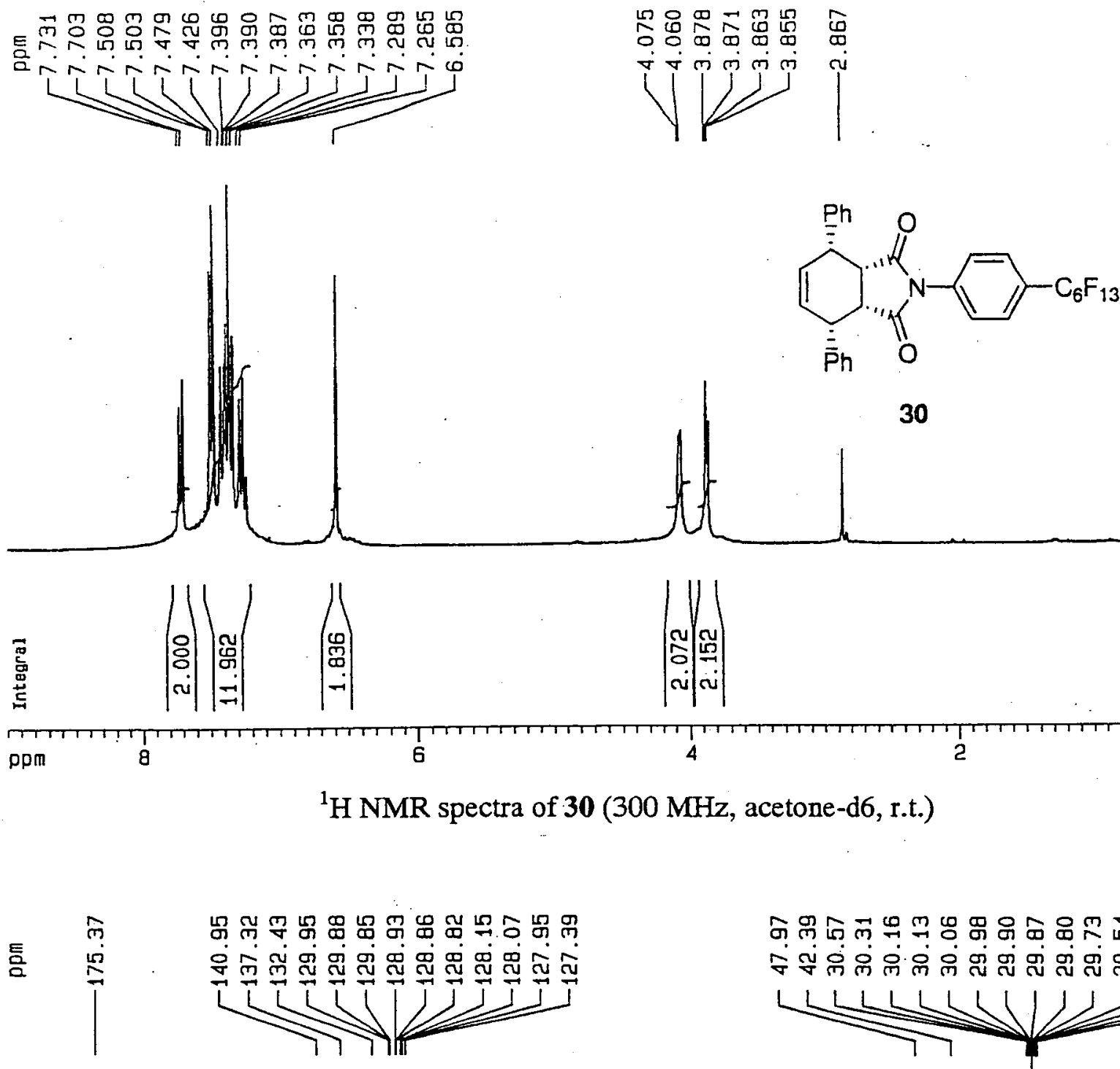

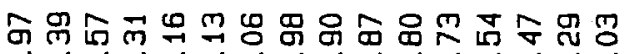

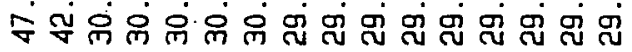<smiles>O=C1[C@H]2[C@H](c3ccccc3)C=C[C@H](c3ccccc3)[C@H]2C(=O)N1c1ccc(C(F)(F)F)cc1</smiles>

30

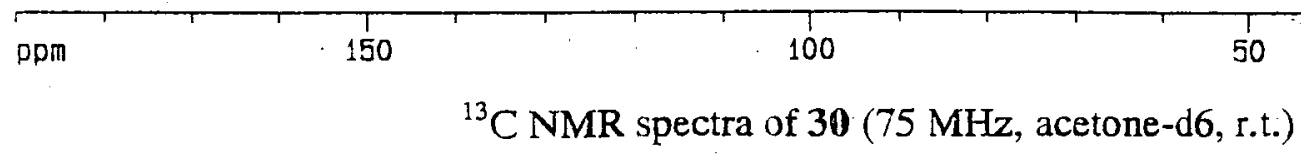




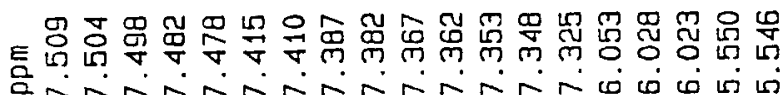
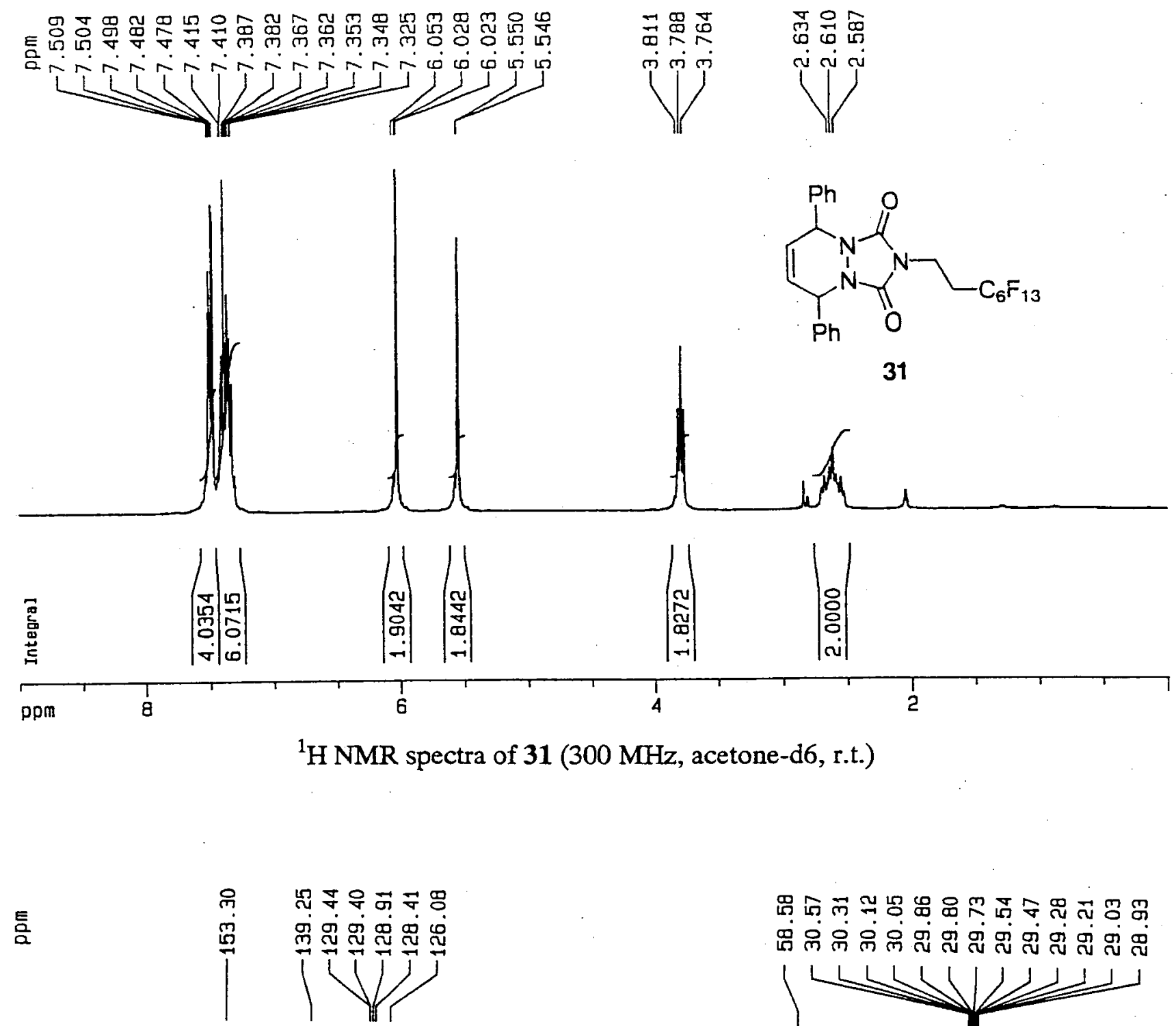

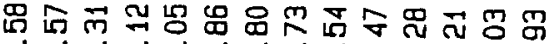

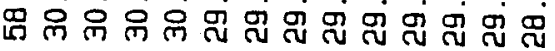

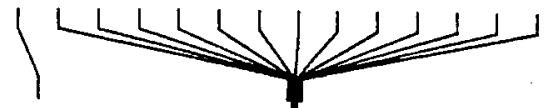

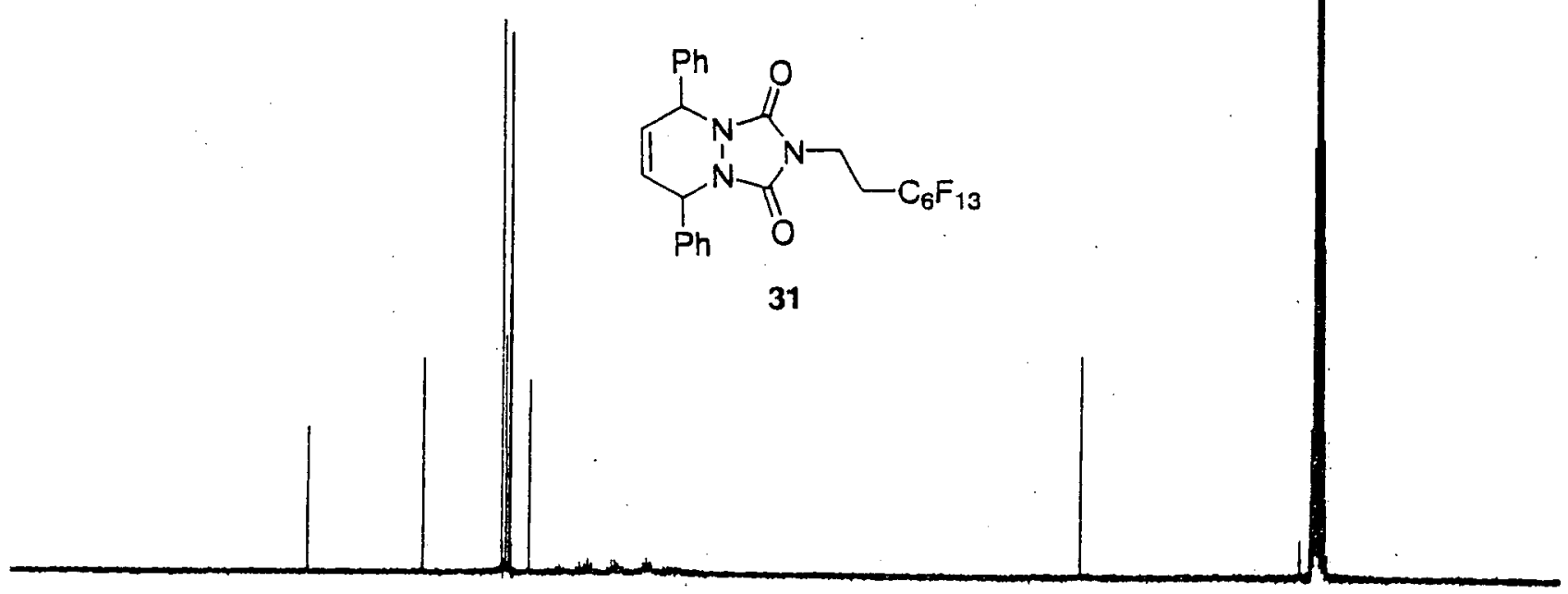

${ }^{13} \mathrm{C}$ NMR spectra of 31 (75 MHz, acetone-d6, r.t.) 
(C) 2003 American Chemical Society, Org. Lett., Werner ol035214a Supporting Info Page 23 B) KINE'IL'SIUDIES

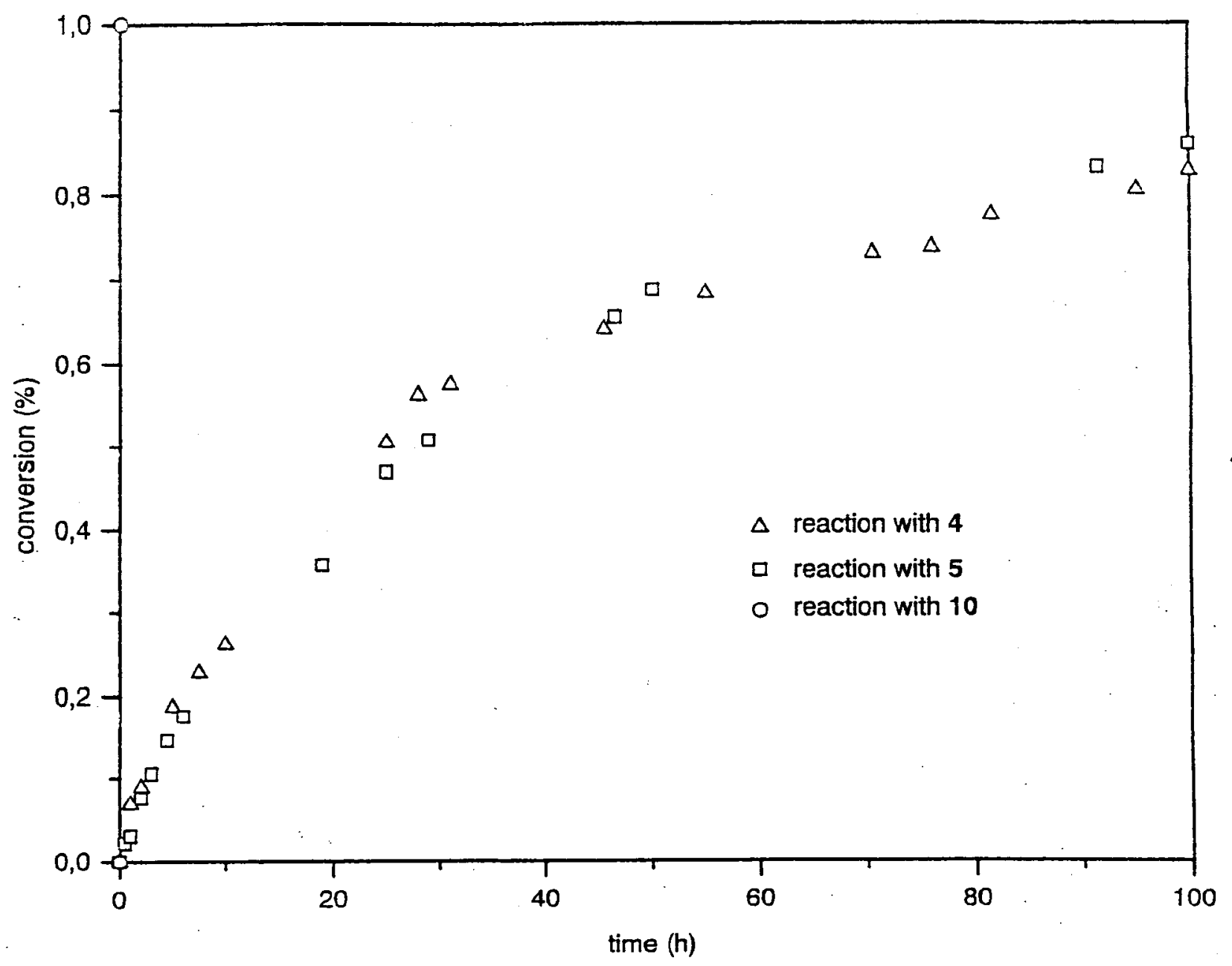

\begin{tabular}{|cc|}
\hline \multicolumn{2}{|c|}{ scavenger 4} \\
time (h) & conersion (\%) \\
\hline 0.0 & 0.000 \\
1.0 & 0.068 \\
2.0 & 0.089 \\
5.0 & 0.187 \\
7.5 & 0.228 \\
10.0 & 0.262 \\
25.0 & 0.504 \\
28.0 & 0.561 \\
31.0 & 0.573 \\
45.5 & 0.640 \\
55.0 & 0.681 \\
70.5 & 0.728 \\
76.0 & 0.735 \\
81.5 & 0.772 \\
95.0 & 0.802 \\
100.0 & 0.825 \\
\hline
\end{tabular}

\begin{tabular}{|cc|}
\hline \multicolumn{2}{|c|}{ scavenger $\mathbf{5}$} \\
time $(\mathrm{h})$ & conersion (\%) \\
\hline 0.0 & 0.000 \\
0.5 & 0.022 \\
1.0 & 0.030 \\
2.0 & 0.075 \\
3.0 & 0.105 \\
4.5 & 0.146 \\
6.0 & 0.176 \\
19.0 & 0.358 \\
25.0 & 0.469 \\
29.0 & 0.507 \\
46.5 & 0.654 \\
50.0 & 0.686 \\
91.5 & 0.829 \\
100.0 & 0.856 \\
\hline
\end{tabular}

\begin{tabular}{|cc|}
\hline \multicolumn{2}{|c|}{ scavenger 10} \\
time $(\mathrm{h})$ & conersion (\%) \\
\hline 0.000 & 0.000 \\
0.083 & 1.000 \\
\hline
\end{tabular}

Reactivity of 4,5 and 10 in a Diels-Alder Reaction with 15 
(c) 2003 American Chemical Society, Org. Lett., Werner ol035214a Supporting Info Page 24

GSE80 0
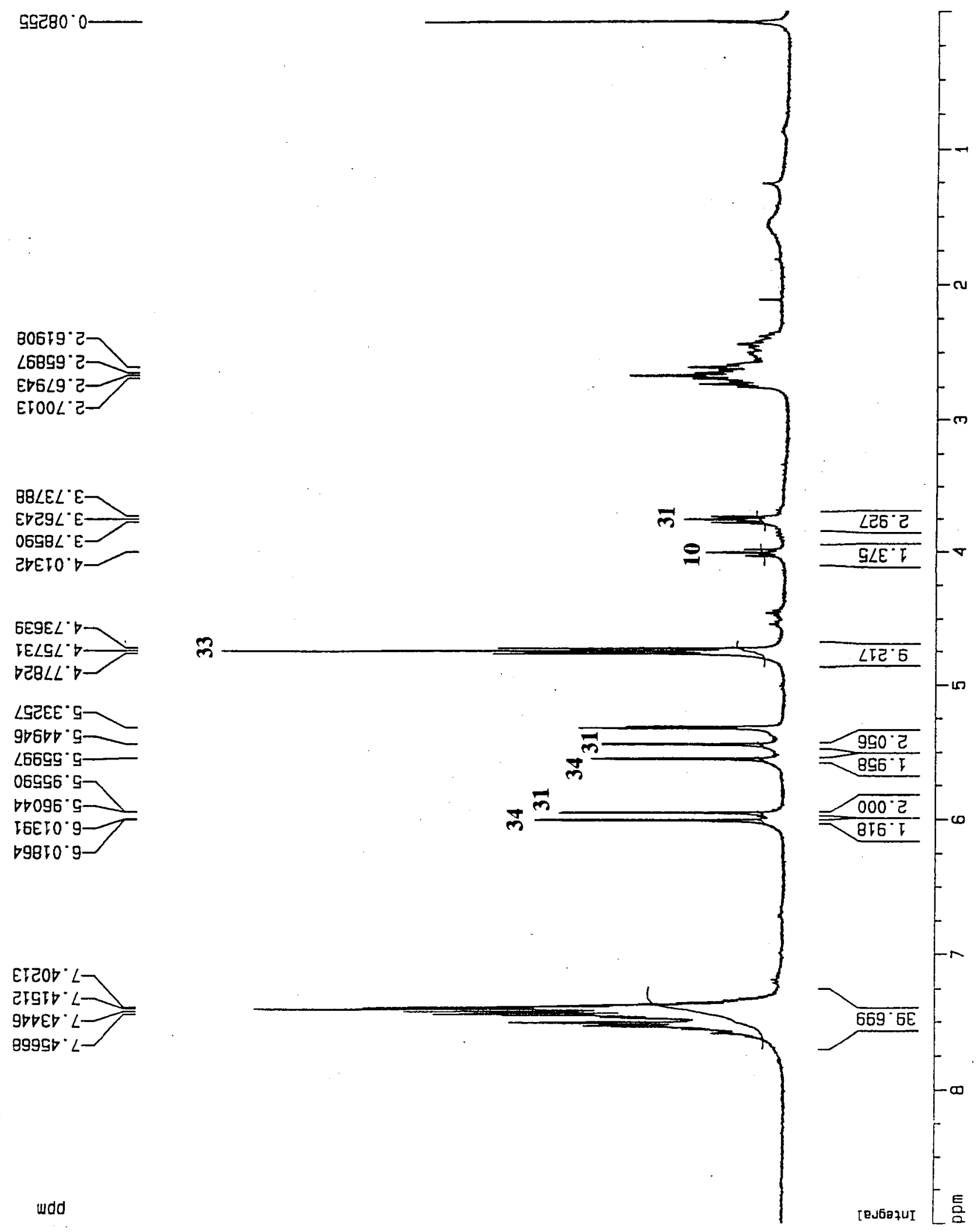

wdd

B8LEL'E

0658 ${ }^{\circ} \mathrm{E}$

ट†EIO० $\square$

GE9E $L^{\circ}$ IELGL" $\square \mathcal{B C L}$

LGZEE' 9 $966 b b^{\circ} \mathrm{Z}$ $\angle 6699^{\circ} 9^{\circ}$ 06596.5 $\forall \vdash 096^{\circ} \mathrm{g}$ IEE I0.9$\checkmark 9810^{\circ} 9$ 
(C) 2003 American Chemical Society, Org. Lett., Werner ol035214a Supporting Info Page 25

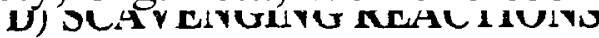

틈 iٓ
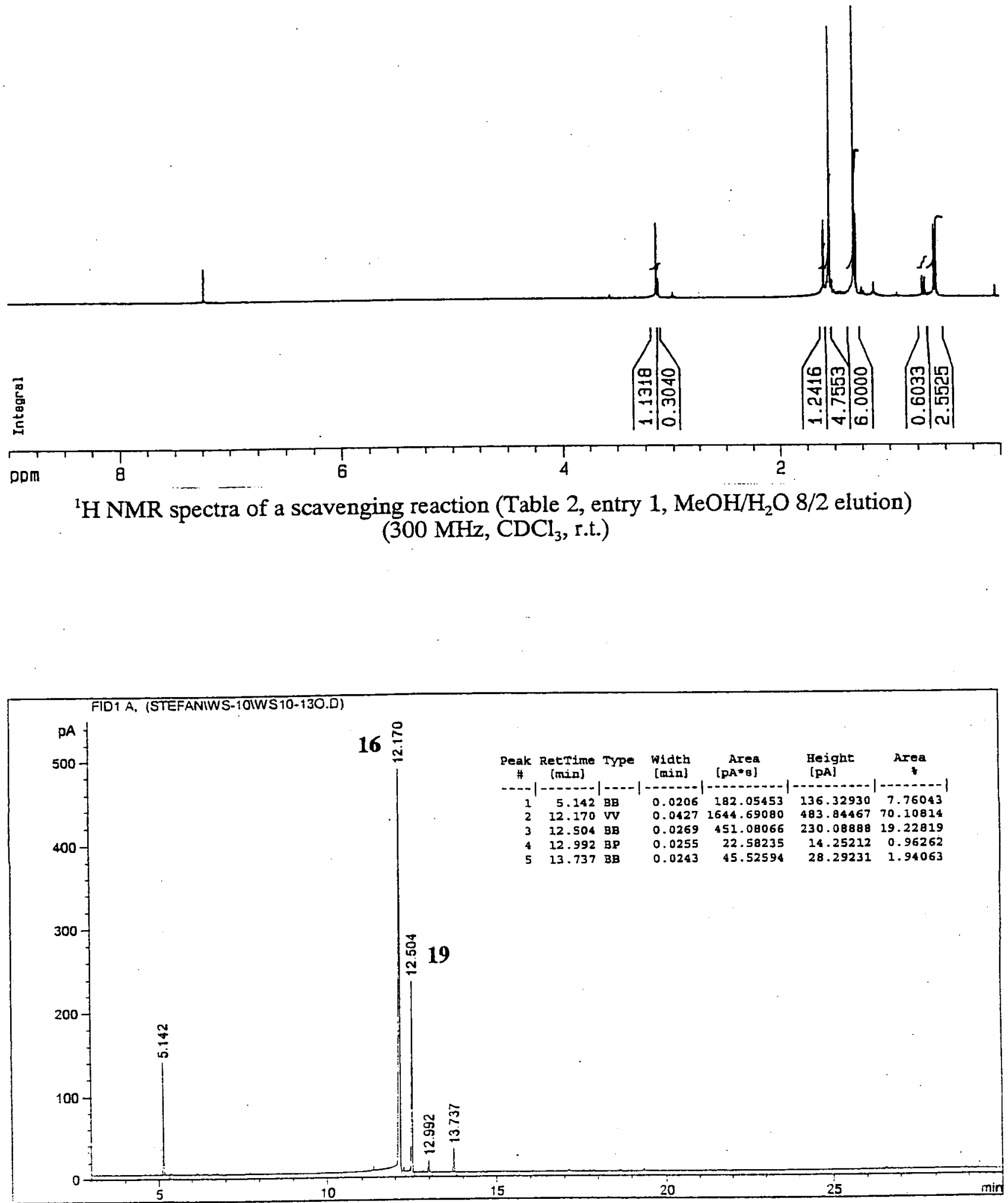

GC chromatogram of a scavenging reaction (Table 2, entry $1, \mathrm{MeOH} / \mathrm{H}_{2} \mathrm{O} 8 / 2$ elution) 
(C) 2003 American Chemical Society, Org. Lett., Werner ol035214a Supporting Info Page 26

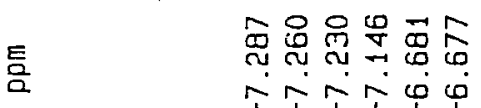

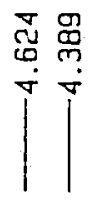

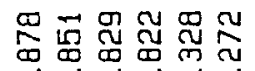

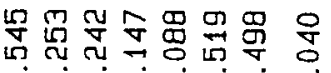

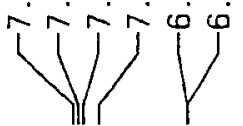

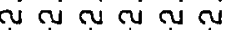

$\dot{r}+\dot{i} \dot{1} \dot{0} 0 \dot{0}$
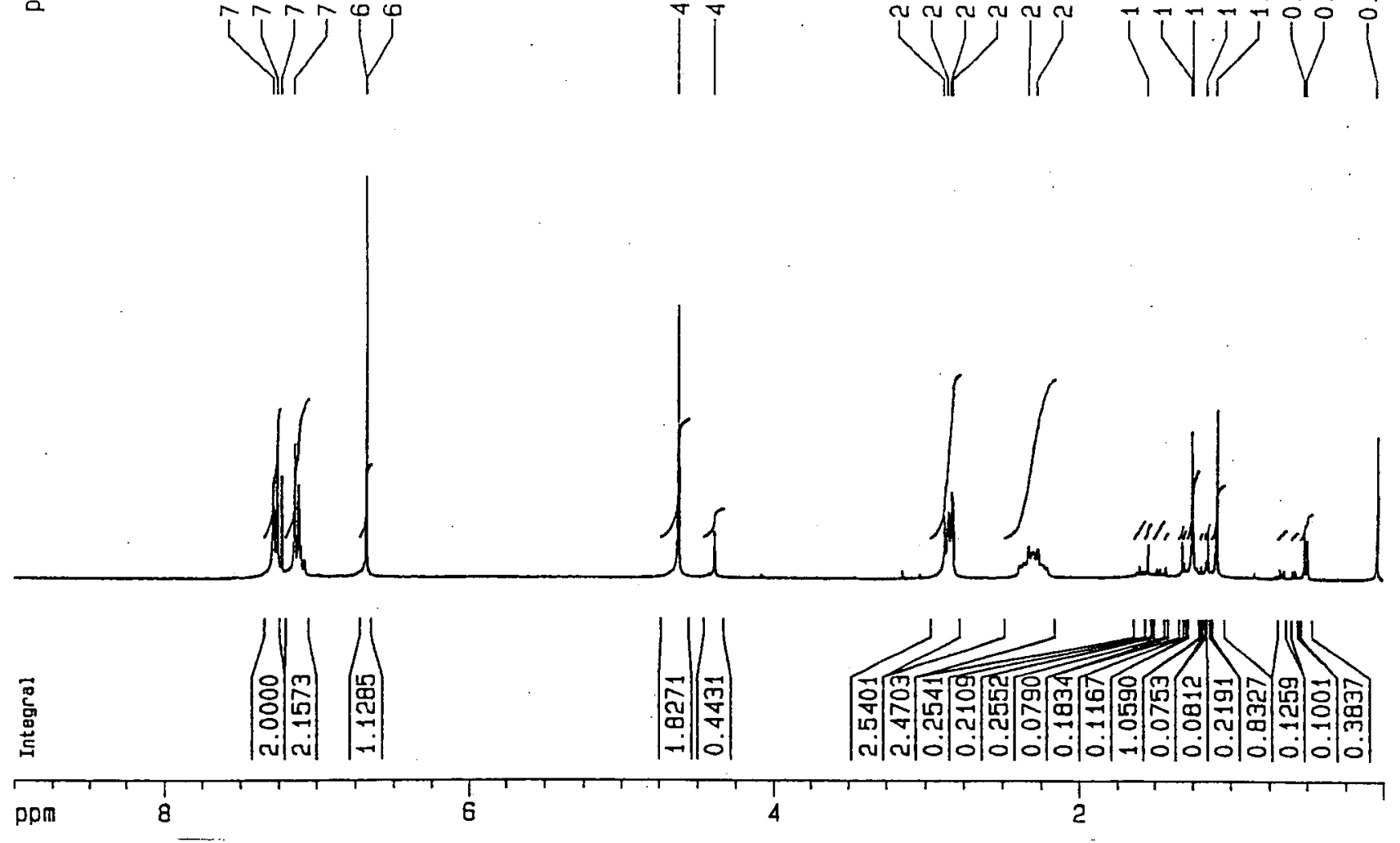

${ }^{1} \mathrm{H}$ NMR spectra of a scavenging reaction (Table 2, entry $1, \mathrm{Et}_{2} \mathrm{O}$ elution) (300 $\mathrm{MHz}, \mathrm{CDCl}_{3}$, r.t.)

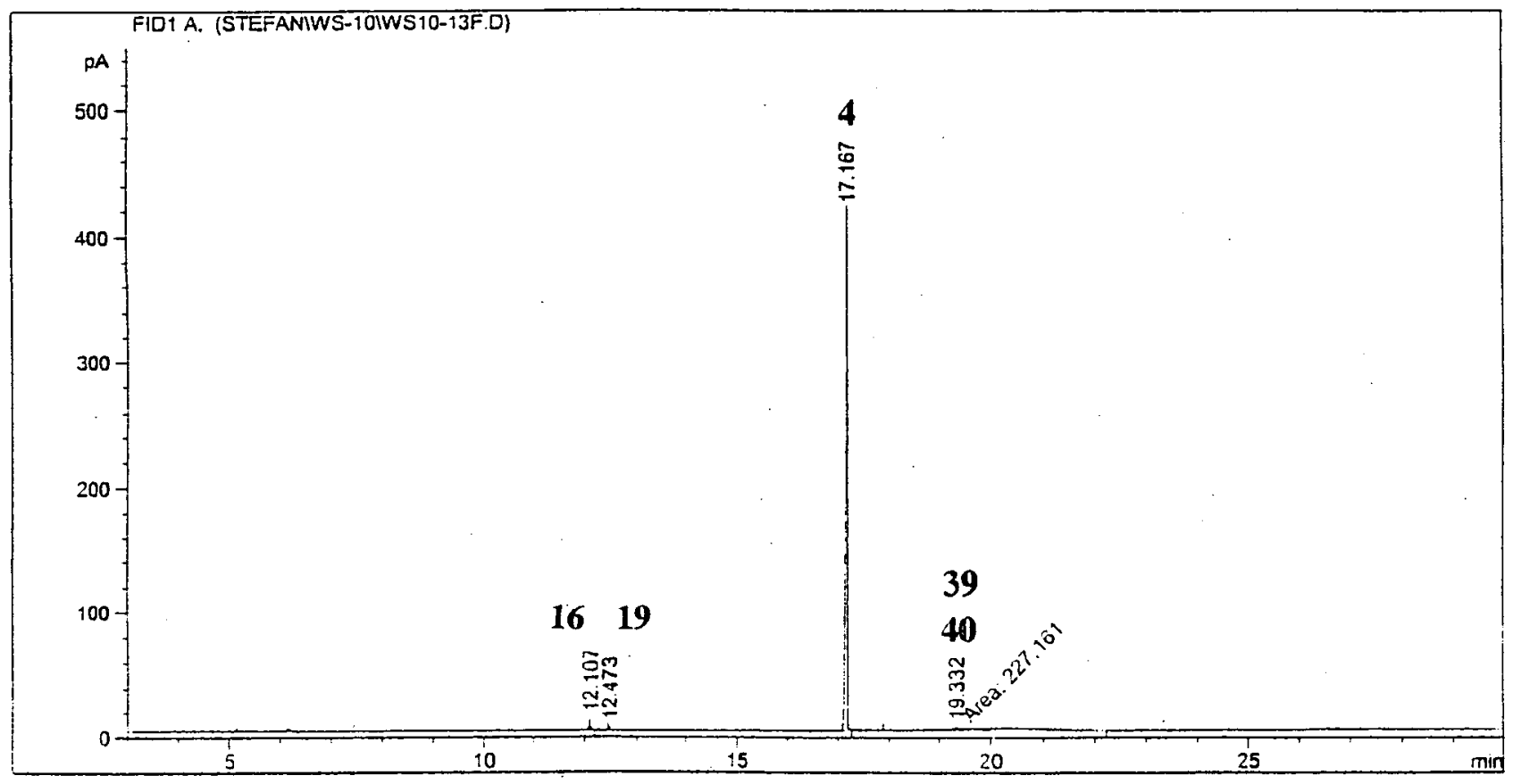

$\mathrm{GC}$ chromatogram of a scavenging reaction (Table 2 , entry $1, \mathrm{Et}_{2} \mathrm{O}$ elution) 
(C) 2003 American Chemical Society, Org. Lett., Werner ol035214a Supporting Info Page 27

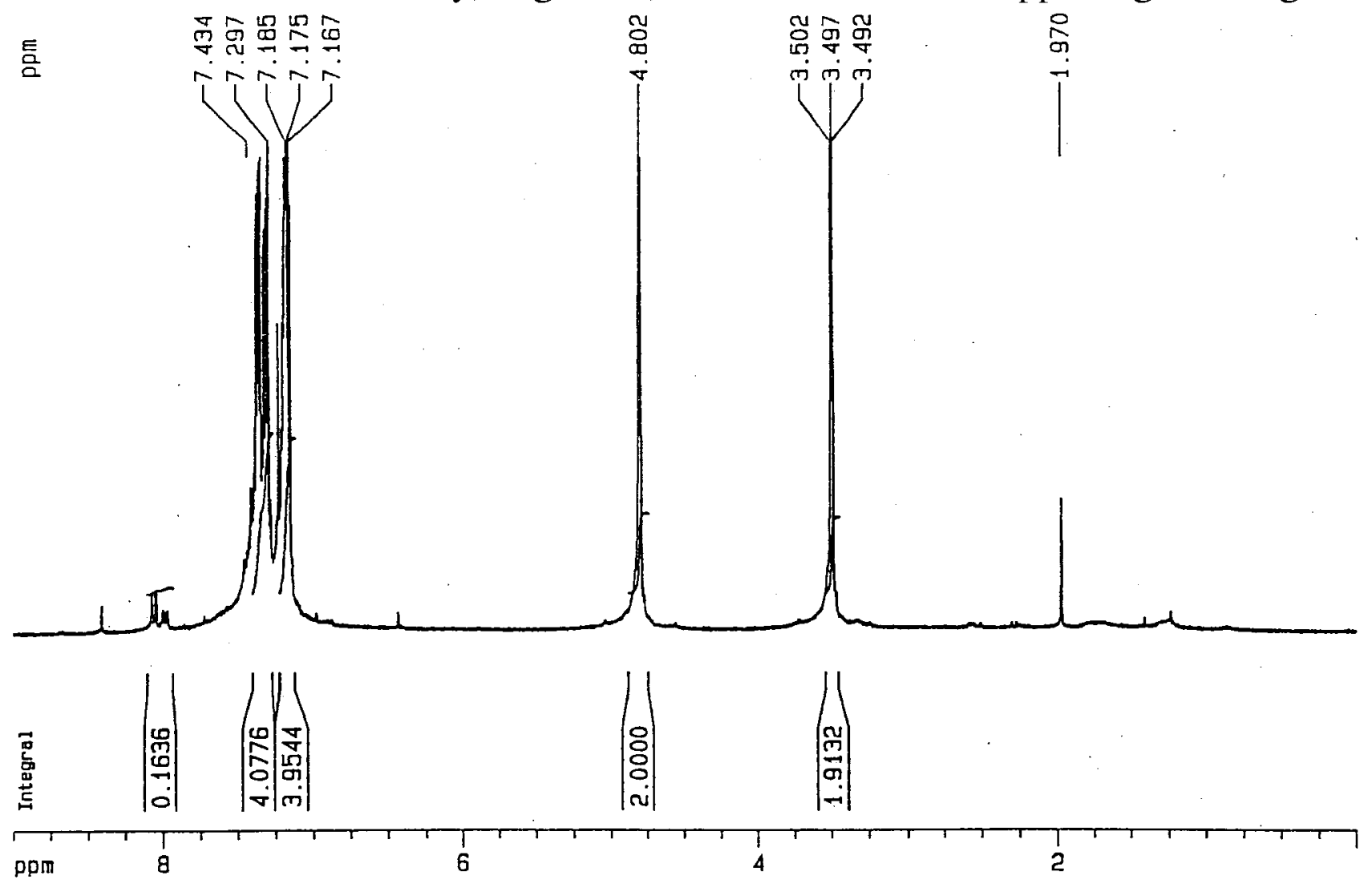

${ }^{1} \mathrm{H}$ NMR spectra of a scavenging reaction under microwave conditions

(Table 2, entry $14, \mathrm{MeOH} / \mathrm{H}_{2} \mathrm{O} 8 / 2$ elution), (300 MHz, $\mathrm{CDCl}_{3}$, r.t.)

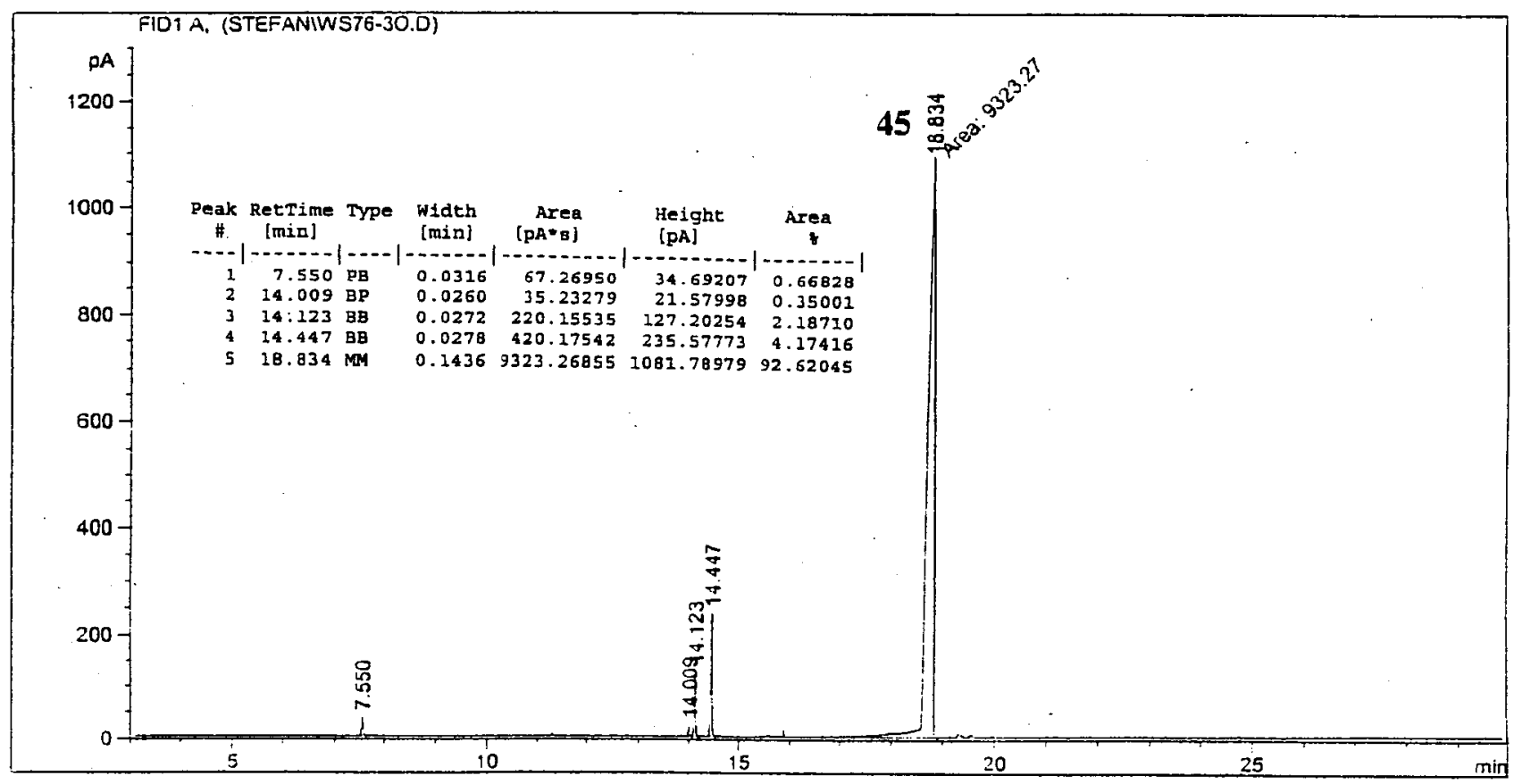

GC chromatogram of a scavenging reaction under microwave conditions

(Table 2, entry $14, \mathrm{MeOH} / \mathrm{H}_{2} \mathrm{O} 8 / 2$ elution) 
(C) 2003 American Chemical Society, Org. Lett., Werner ol035214a Supporting Info Page 28
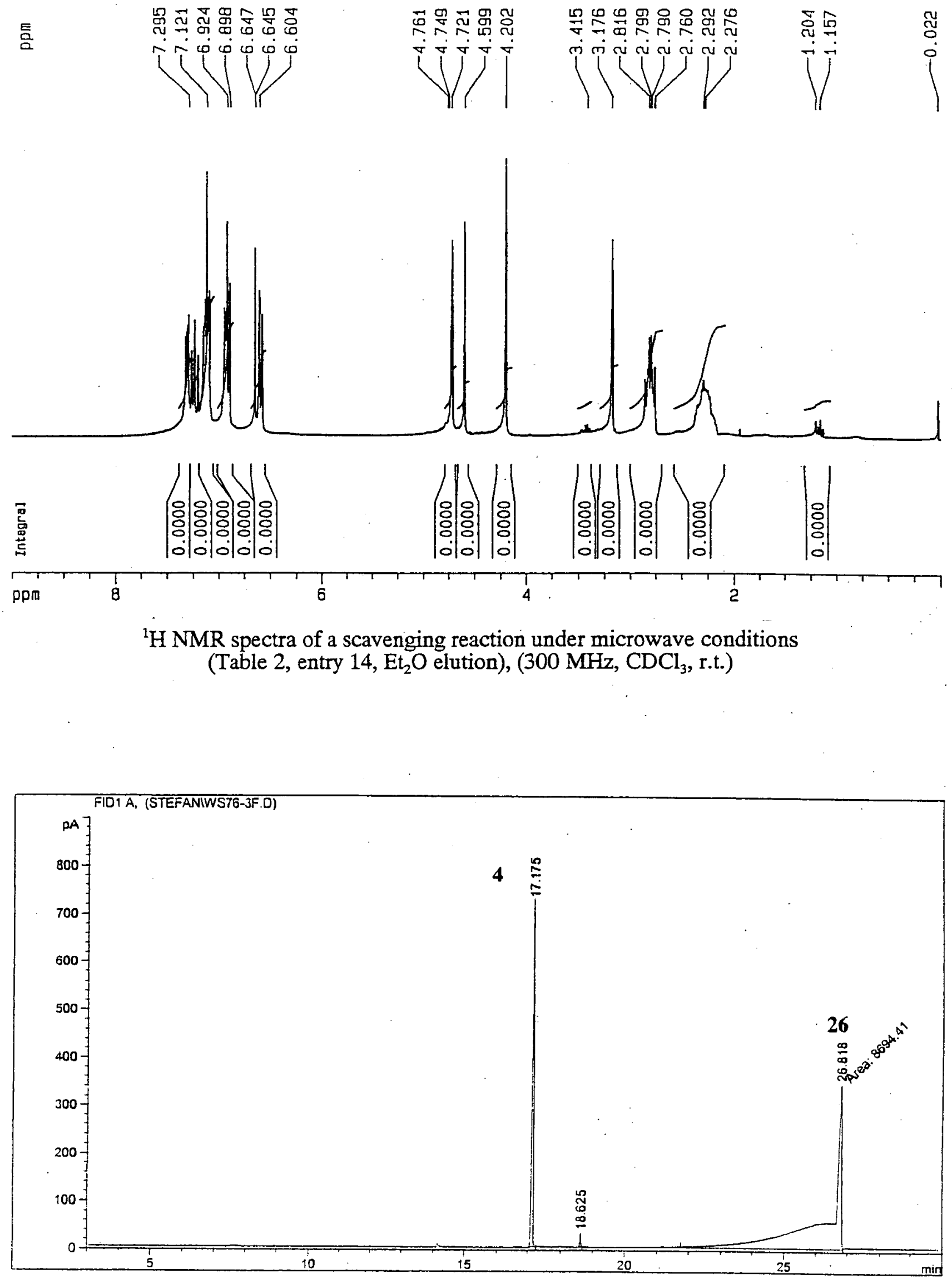

GC chromatogram of a scavenging reaction under microwave conditions (Table 2, entry $14, \mathrm{Et}_{2} \mathrm{O}$ elution) 